\title{
Gold, Silver, and Electrum Electroless Plating on Additively Manufactured Laser Powder-Bed Fusion AlSi10Mg Parts: A Review
}

\author{
Dana Ashkenazi 1,*(D), Alexandra Inberg ${ }^{2}$, Yosi Shacham-Diamand ${ }^{2,3}$ and Adin Stern ${ }^{4,5}$ \\ 1 School of Mechanical Engineering, Tel Aviv University, Ramat Aviv 6997801, Israel \\ 2 School of Electrical Engineering, Tel Aviv University, Ramat Aviv 6997801, Israel; inberg@tauex.tau.ac.il (A.I.); \\ yosish@tauex.tau.ac.il (Y.S.-D.) \\ 3 Department of Materials Science and Engineering, Tel Aviv University, Ramat Aviv 6997801, Israel \\ 4 Department of Mechanical Engineering, Afeka Academic College of Engineering, Tel Aviv 6910717, Israel; \\ aandls@gmail.com \\ 5 Department of Materials Engineering, Ben-Gurion University of the Negev, Beer Sheva 8410501, Israel \\ * Correspondence: danaa@tauex.tau.ac.il; Tel.: +972-3-6405579
}

Citation: Ashkenazi, D.; Inberg, A.; Shacham-Diamand, Y.; Stern, A. Gold, Silver, and Electrum Electroless Plating on Additively Manufactured Laser Powder-Bed Fusion AlSi10Mg Parts: A Review. Coatings 2021, 11, 422. https://doi.org/10.3390/ coatings11040422

Academic Editor: Zhao Zhang

Received: 22 February 2021

Accepted: 3 April 2021

Published: 6 April 2021

Publisher's Note: MDPI stays neutral with regard to jurisdictional claims in published maps and institutional affiliations.

Copyright: (c) 2021 by the authors. Licensee MDPI, Basel, Switzerland. This article is an open access article distributed under the terms and conditions of the Creative Commons Attribution (CC BY) license (https:// creativecommons.org/licenses/by/ $4.0 /)$.

\begin{abstract}
Additive manufacturing (AM) revolutionary technologies open new opportunities and challenges. They allow low-cost manufacturing of parts with complex geometries and short timeto-market of products that can be exclusively customized. Additive manufactured parts often need post-printing surface modification. This study aims to review novel environmental-friendly surface finishing process of 3D-printed AlSi10Mg parts by electroless deposition of gold, silver, and gold-silver alloy (e.g., electrum) and to propose a full process methodology suitable for effective metallization. This deposition technique is simple and low cost method, allowing the metallization of both conductive and insulating materials. The AlSi10Mg parts were produced by the additive manufacturing laser powder bed fusion (AM-LPBF) process. Gold, silver, and their alloys were chosen as coatings due to their esthetic appearance, good corrosion resistance, and excellent electrical and thermal conductivity. The metals were deposited on 3D-printed disk-shaped specimens at 80 and $90^{\circ} \mathrm{C}$ using a dedicated surface activation method where special functionalization of the printed AlSi10Mg was performed to assure a uniform catalytic surface yielding a good adhesion of the deposited metal to the substrate. Various methods were used to examine the coating quality, including light microscopy, optical profilometry, XRD, X-ray fluorescence, SEM-energy-dispersive spectroscopy (EDS), focused ion beam (FIB)-SEM, and XPS analyses. The results indicate that the developed coatings yield satisfactory quality, and the suggested surface finishing process can be used for many AM products and applications.
\end{abstract}

Keywords: additive manufacturing; AlSi10Mg; electroless deposition; gold-silver coatings; laser powder bed fusion; surface modification

\section{Introduction}

\subsection{Additive Manufacturing}

The AlSi10Mg alloy belongs to the hypoeutectic aluminum-silicon group [1]. This alloy has good fluidity accompanied by low shrinkage, making it an important cast alloy with excellent weldability. AlSi10Mg contains about $0.4 \mathrm{wt} . \% \mathrm{Mg}$, making the alloy a heat treatable material that responds to the precipitation hardening processes [2]. Adding $\mathrm{Mg}$ to the Al-Si alloy allows the formation of $\mathrm{Mg}_{2} \mathrm{Si}$ precipitations, which considerably strengthens the matrix without reducing other mechanical properties [1]. The alloy is also hardened by rapid solidification, where high cooling rates are imposed, refining the microstructure [3].

A high strength/weight ratio, lighter weights, and higher corrosion resistance of aluminum alloys enable their easy replacement for other materials in different engineering applications [4]. Recently, additive manufacturing (AM) technologies have been applied for 
fabricating lightweight parts of simple and complex shapes to be used by different engineering sectors. Additive manufacturing has been used for various materials, including metals and their alloys. The overall AlSi10Mg alloy properties make the material ideally suitable for processing using the laser powder bed fusion (LPBF) AM technology and adoption of the alloy by many industries, including the aerospace and automotive sectors [4-6]. To ensure the high quality of printed specimens, it is essential to understand the impact of both the LPBF process parameters and the material feedstock properties on the quality of the parts [7], including the plastic anisotropic behavior; a notable lower ductility is typically observed for the vertical printed tensile samples when compared to their respective horizontal samples [4-8]. Namely, the study of the unique LPBF solidification conditions and the material's thermal history may lead to the understanding of the characteristic defects (porosity, hot cracking phenomena, and surface roughness), observed in AlSi10Mg alloy components produced by the LPBF technique $[6,7]$. The surface quality depends on the intrinsic material properties as well as on the scan strategies during printing, i.e., contour scans and skywriting scans. The roughness is typically caused by the parallel running welding beads and by stairs effect [9].

So far, many studies have investigated the influence of the LPBF process parameters (i.e., thickness of the printed layer, laser power, scanning speed, build-strategy, chamber atmosphere etc.) on the quality of the LPBF parts. For example, Yang studied the influence of process parameters, such as laser power and scanning speed, on the vertical surface roughness of the AlSi10Mg parts fabricated by LPBF process [9]. Steuben et al. 2019 discussed the use of a computational enriched analytical solution method (EASM) for AM modeling and simulation in order to predict the influence of process parameters on the properties and associated functional performance of the LPBF parts [10]. Understanding the influence of main LPBF processing parameters on the surface roughness of AM components can be used for additional process optimization [11]. Surface post-processing techniques, such as heat treatment, shot peening, polishing, sand blasting, and coatings [12], and the resulting part qualities for the AlSi10Mg alloy have been discussed before [13-15]. Yet, surface post-processing techniques increase the production time and cost [12].

In this paper, we add more information on post-AM surface modification, presenting a novel finishing process and suggesting a methodology for electroless plating of silver, gold, and their alloys as a method to improve surface quality, both physical and ornamental.

\subsection{Electroless Plating of Gold, Silver and Au-Ag Alloys}

The quality of the surface finish of 3D-printed parts produced by the AM-LPBF is occasionally unsuitable for applications demanding, for example, low roughness and uniformity. Therefore, additional post-AM surface modification processes, such as machine finishing techniques and coatings, are frequently applied [16]. Different metallic coatings are often used, improving electrical, thermal, optical, and mechanical properties, as well as erosion and corrosion resistance, and achieving a decorative appearance of the AMprinted parts. See, for example, the paper by Kuo et al. 2017, which specifically stated that improving the surface quality of additive manufactured parts by minimizing the roughness of the surface is a promising engineering topic, which can be achieved by coating the printed surface [17]. The quality of the coating depends on various factors, including the parameters of the AM process, e.g., the position and orientation, and the presence of external defects, the part's surface roughness, and the cleaning process of the surface before coating [18].

Metal deposition of thin films is accomplished by either physical, chemical, or electrochemical methods, such as physical vapor deposition (PVD), chemical vapor deposition (CVD), and electrochemical deposition (ECD). Electroless deposition (ELD), which is an electrochemical method, is promising for printed metal surface finishing, since it is rather simple, relatively (to other methods) inexpensive and, most importantly, it yields good results [19]. For instant, ELD may be used for the production of 3D-printed micro circuitries for structural electronic devices [16]. 
The electroless plating process is based on the simultaneous metal reduction and reducing-agent oxidation on an activated surface, where the heterogeneous reactions continue in an autocatalytic form until the depletion of one of the components (or both), assuming the bath conditions, such as $\mathrm{pH}$ and temperature, are kept unchanged [19]. The electrons for the chemical reduction are provided by the oxidation of a reducing agent [20]. Hence, the electroless plating occurs without the use of an external current source, and therefore, it requires a relatively simple bath and control and support units. The electroless process occurs in an aqueous bath, which is relatively simpler than that of other metal and alloy deposition such as vacuum-based PVD and CVD equipment [21-25]. In this self-initiating auto-catalytic process, a catalytic substrate is dipped into an aqueous solution containing metal ions (typically in a complex form), reducing agents, and $\mathrm{pH}$ adjustment components $[19,23]$. In a few cases, the bath may include also special additives in a minute amount for special functions such as brightening or leveling [19]. ELD is a controlled method, which has been used industrially for many years, it operates at a moderately low temperature $\left(<100{ }^{\circ} \mathrm{C}\right)$, and allows high selectivity depositions on both conductive and non-conductive surfaces [20-23]. The ELD technique provides relatively uniform thickness of metal and alloy deposits. For example, according to Shacham-Diamand et al. 2000 [26] and Shukla et al. 2014 [27], electroless silver deposition produces high-quality coating with a thickness of up to about $1 \mu \mathrm{m}$ [26-28]. This technique is particularly effective in the case of deep pores and rough surfaces [28].

ELD manufacturing of nickel-phosphorus (Ni-P) was developed by Brenner and Riddell [29] in the mid-1940s, and since then, it has been frequently used in numerous industries as a protective layer [30]. For example, Ni-P film is commonly applied atop porous surfaces [31]. Crystallization and phase transformation processes of ELD Ni-P film during thermal processing have roles in determining the material properties [32]. By applying an ELD Ni-P layer on top of an aluminum alloy substrate, the material properties, such as corrosion resistance, wear resistance, and hardness may be significantly improved [33,34]. In addition, according to Asher et al. 2009, self-assembled monolayers (SAMs), such as functional silanes SAMs, may also be applied in order to improve the metal adhesion to oxidized surfaces [21].

Gold and silver were among the first metals used by ancient societies; both are transition metals with shiny appearances [35]. Gold and silver have excellent corrosion resistance, they are soft, ductile, and malleable metals with superb reflectivity and high electrical and thermal conductivity [36,37]. Electrum, a gold-silver alloy that usually contains 60 wt. \%-80 wt.\% Au and 20 wt.\%-40 wt.\% Ag [38], was initially used during the first millennium BCE. The first known metal coins used in antiquity, which were dated to 630-620 BCE, were made of electrum [35]. Some ancient electrum items contain more than 20 wt. $\%-40$ wt.\% silver [39,40]. For instance, according to Ashkenazi et al. 2017, the fourth century BCE electrum bar with granules from the Nablus Hoard was composed of 21.6 wt. $\%-64.5$ wt.\% Au and 35.5 wt.\%-77.4 wt.\% Ag [35].

Applying gold, silver, and electrum coatings over objects made of aluminum alloys can efficiently shield the parts against corrosion in many severe environments, for instance, protection against pitting corrosion of $\mathrm{Al}$ in a surrounding of $\mathrm{NaCl}$ solutions [36]. Silver deposition is often used to coat aluminum micro-mirrors when high reflectivity is needed in the visible light, near infrared light, and radio frequency wavelengths [41].

There are different industrial gold and silver ELD processes employing various formulations. However, the associated published technological information is limited as a result of commercial confidentiality. In addition, industrial processes commonly use environmentally hazardous materials such as cyanide compounds [42,43]. A few studies have been published on the electrochemical deposition of Au-Ag alloy films [44-47]. However, no formulations of ELD for Au-Ag alloy coatings have been published in the open literature before Inberg et al. 2020 [48].

Electroless gold, silver, and electrum coatings can be useful to improve the properties of AM-LPBF parts for many applications. For example, in some AM-LPBF A1Si10Mg 
items, additional coatings may be needed to improve electrical and thermal conductivity or to achieve a certain aesthetic appearance. The shiny and luxurious appearance of gold [43], silver [42], and electrum [48] plating can be used in numerous applications, among them replicas of ancient objects, such as valuable coins for museum presentations [42,43]. ELD of gold [49] and silver [50] metals can also be applied over AM fused filament fabrication (AM-FFF) acrylonitrile butadiene styrene (ABS) polymer objects when an appropriate chemical pretreatment process of the surface is done $[49,50]$.

The objective of this research is to study the use of a novel environmentally friendly ELD finishing process by gold, silver, and electrum, of AM-LPBF AlSi10Mg parts, as a part of their post-printing surface modification. In addition, based on previous work of Dresler et al. 2019 [42] and Inberg et al. 2020 [43,48], this review aims to propose a methodology for effective Au, Ag, and Au-Ag ELD coatings of AM-LPBF AlSi10Mg objects. We should point out that one of the highlights of the technologies described here is the surface activation method. Since electroless plating is an autocatalytic process, it requires a high-quality catalytic surface to initiate the deposition. Any defect in the pre-deposition process will show up in the final coating. Hence, the SAM surface modification, which was developed by Osaka and his research group [51], may contribute to the success of the proposed process. That method was developed originally for a silicon dioxide surface as a barrier layer. However, it can be applied for other oxidized materials, in our case to AlSi10Mg, allowing the formation of a stable bond between the SAM adhesion layer and the substrate.

\section{Materials and Experimental Methods}

\subsection{AM-LPBF AlSi10Mg Disk-Shaped Specimens}

The $26 \mathrm{~mm}$ diameter disk-shaped samples (Figure 1) and coin replica specimens were fabricated with an EOSINT M 280 instrument (EOS Company, Krailling, Germany), which uses the conventional AM-LPBF process. The samples were additively built directly from computer-aided design (CAD) data (Figure 1a-c). The disk-shaped samples, which were designed to simulate the look and geometry of ancient metal coins, consist of an obverse side with two steps (1 mm height each) and a reverse side with planar surface. The printing compartment was controlled under argon flow (up to maximal oxygen content of $0.12 \%$ ), which lowers the alloy oxidation during the process. The chemical composition of the as-received AlSi10Mg feedstock is shown in Table 1. The particle-size distribution showed particles ranging between 15 and $75 \mu \mathrm{m}$. Scanning electron micrographs reveal that the powders show an irregular particles shape with a low quantity of elongated particles and only a limited satellite attachment on the powder surface (Figure 2a). The powder's microstructure (Figure $2 b$ ) consists of a primary $\alpha$-Al matrix with cellular-dendritic and eutectic microstructures with very fine fibrous $\mathrm{Si}$; some scattered micron size porosity is also evident [42]. 


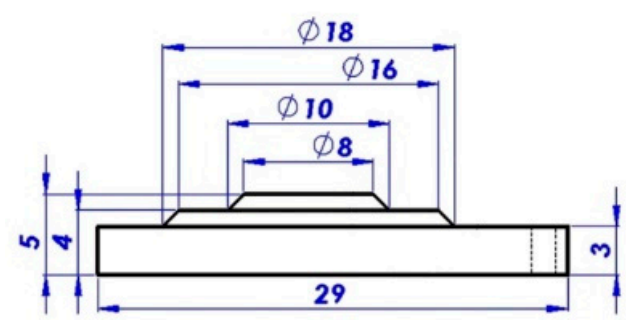

(a)

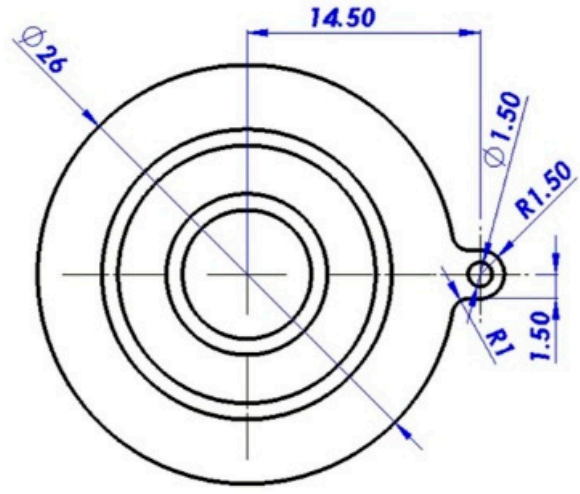

(b)

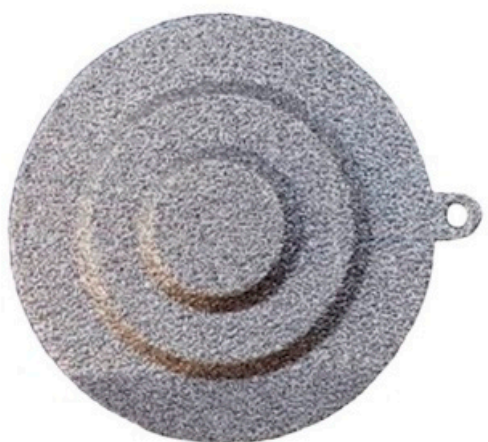

(d)

Figure 1. The disk-shaped configuration: (a) front view computer-aided design (CAD) model; (b) top view CAD model; (c) isometric view CAD model, showing the Z-direction (blue arrow); and (d) typical additive manufacturing laser powder-bed fusion (AM-LPBF) 3D-printed AlSi10Mg specimen.

Table 1. The chemical composition of the AlSi10Mg powder: Basic standard: BS EN 1706:2020.

\begin{tabular}{cccccccccc}
\hline \multirow{2}{*}{ Alloy } & \multicolumn{7}{c}{ Composition (wt \%) } \\
\cline { 2 - 9 } & Si & Mg & Fe & $\begin{array}{c}\text { Cu, Mn, Zn, } \\
\text { Ni, Pn, Sn }\end{array}$ & Ti & Al & O & N \\
\hline \multirow{2}{*}{1706} & $9.0-$ & $\begin{array}{c}0.20- \\
0.45\end{array}$ & $\leq 0.55$ & $\leq 0.1$ & $\leq 0.15$ & Bal. & N.A. & N.A. \\
\hline
\end{tabular}

The specimens (Figure 1d) were printed with a $400 \mathrm{~W}$ continuous Yb:YAG fiber laser beam (laser beam diameter $\approx 100 \mu \mathrm{m}$ ) along the vertical Z-axis (Figure $1 \mathrm{c}$ ) with a scanning velocity of $\approx 1 \mathrm{~m} \cdot \mathrm{s}^{-1}$. The temperature of the $250 \mathrm{~mm} \times 250 \mathrm{~mm} \times 300 \mathrm{~mm}$ build-platform was about $35{ }^{\circ} \mathrm{C}$ through the manufacturing process. An average layer thickness of $\approx 60$ $\mu \mathrm{m}$ prior to melting led to a solid layer thickness of $\approx 30 \mu \mathrm{m}$ after solidification. A post T5 heat treatment was performed on the as-built specimens, i.e., holding the disk-shape specimens for $2 \mathrm{~h}$ at $300{ }^{\circ} \mathrm{C}$ in an air-furnace followed by furnace cooling [42]. 

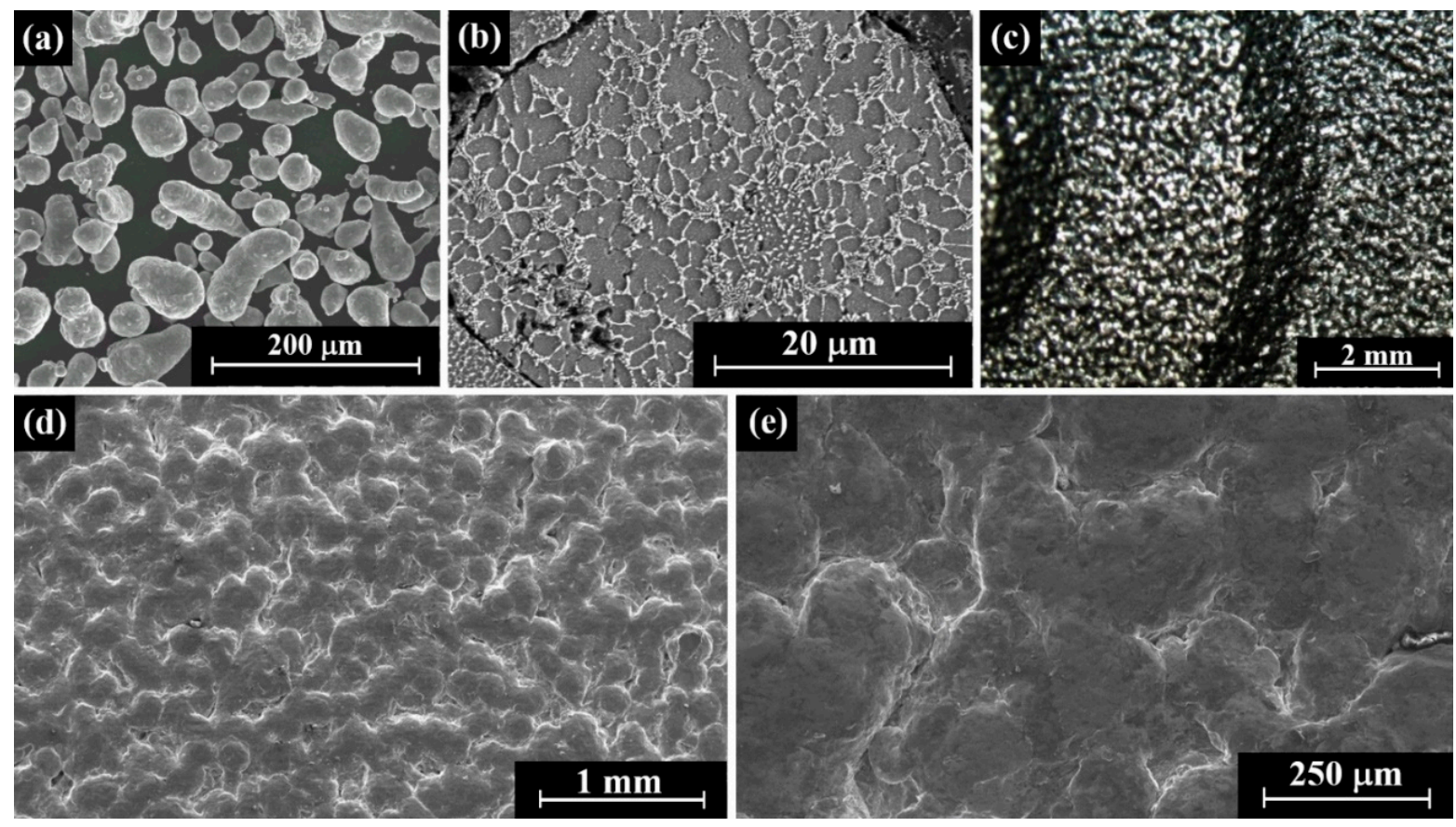

Figure 2. The representative surface of an as-printed AM-LPBF AlSi10Mg disk-shaped reference specimen (obverse): (a) AlSi10Mg feedstock, typical powder particles (SEM); (b) AlSi10Mg characteristic particle's cross-section; (c) a general view of the as-printed disk-shaped specimen (multi-focal light microscope); and (d,e) higher magnifications of the diskshaped specimen surface (SEM).

\subsection{Silver Electroless Plating on AM-LPBF AlSi10Mg}

A silver electroless deposition bath (Figure 3, Table 2) was developed at Tel Aviv University (TAU) by Dresler et al. 2019 [42]. This electroless plating process was published earlier by Shacham-Diamand et al. 2000 [26]; however, it was never examined on the AlSi10Mg alloy or on any 3D-printed objects until 2019 [42]. The silver film was deposited by electroless plating on top of disk-shaped substrates covered with native oxide film (Figure 3a), according to the TAU process protocol [42]. The deposition process was applied at room temperature from an $\mathrm{AgNO}_{3}$ base solution with hydrazine hydrate, $\mathrm{N}_{2} \mathrm{H}_{4}$, as the reducing agent that was totally oxidized due to the $\mathrm{N}_{2} \mathrm{H}_{4}+4 \mathrm{OH}^{-}-4 \mathrm{e} \rightarrow \mathrm{N}_{2}+$ $4 \mathrm{H}_{2} \mathrm{O}$ anodic reaction. Therefore, no hazardous products remained in the electrolyte after the silver deposition. Ammonia and acetic acid were used to complex the metal ions and to preserve the working $\mathrm{pH}$ in the range of 10.0-10.6, e.g., creating an ammonium-acetate buffer solution. This relatively stable bath was selected, since it yielded good quality silver coatings on many metal substrates without the need for brighteners [26].

Table 2. The electroless silver bath composition. Adapted with permission from [26,42]. Copyright 2020 Copyright IOPscience. Copyright 2019 Copyright Springer.

\begin{tabular}{cc}
\hline Component & Concentration (M) \\
\hline Silver nitrate $\left(\mathrm{AgNO}_{3}\right)$ & 0.03 \\
Ammonia $\left(\mathrm{NH}_{4} \mathrm{OH}\right)$ & 1.0 \\
Acetic acid $\left(\mathrm{CH}_{3} \mathrm{COOH}\right)$ & 0.5 \\
\hline
\end{tabular}




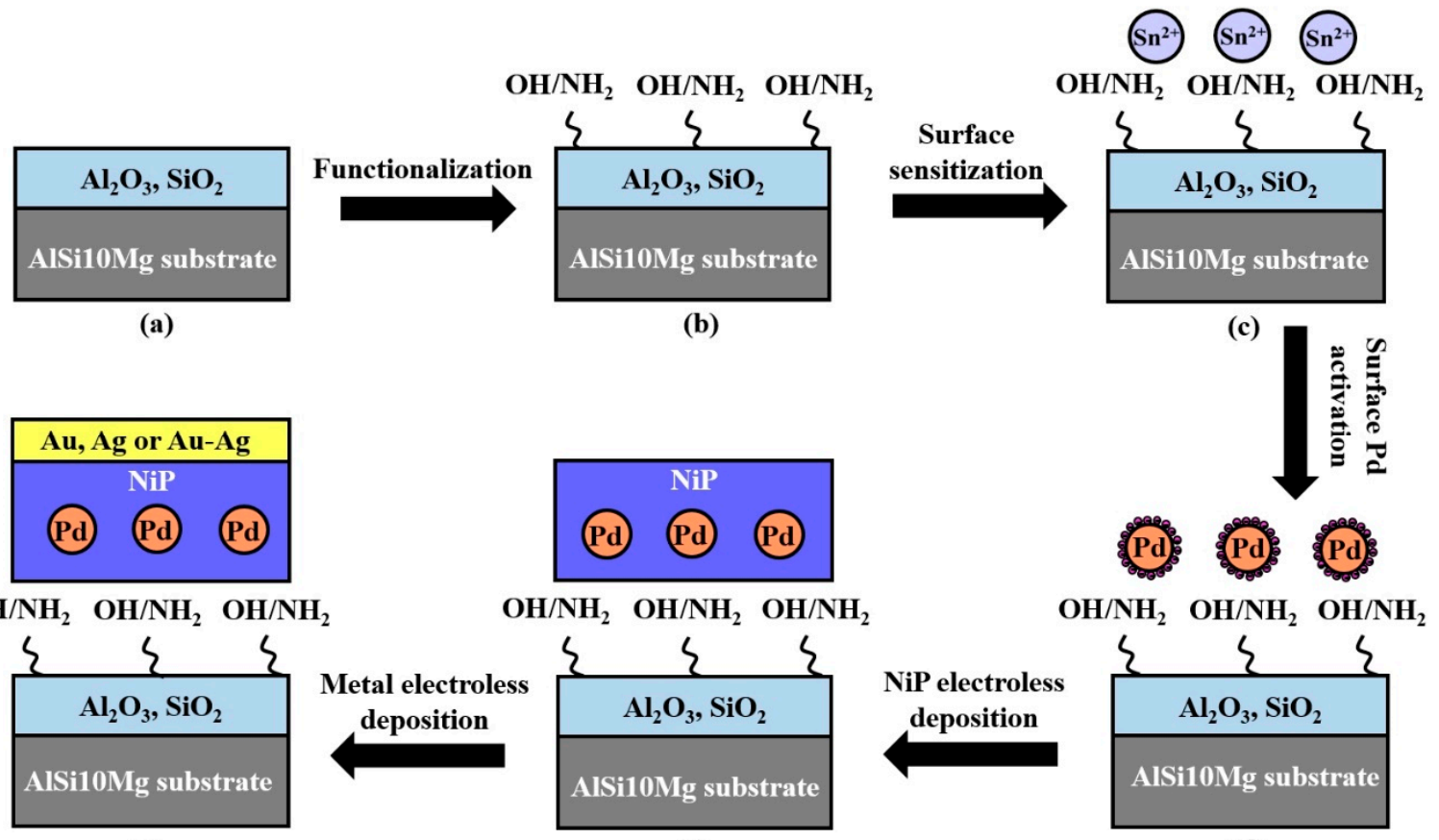

(f)

(e)

(d)

Figure 3. Schematic illustration of the gold, silver, and electrum electroless plating process developed for the AM-LPBF AlSi10Mg surface coating: (a) The 3D-printed AlSi10Mg substrate covered with native oxide (Mg is not presented here since AlSi10Mg contains less than $0.5 \mathrm{wt} . \% \mathrm{Mg}$ ); (b) surface functionalization: sodium dodecyl sulfate (SDS)/silanization; (c) surface sensitization (optional), (d) surface Pd activation; (e) deposition of Ni-P interlayer (optional); and (f) electroless deposition of metal coating [42,43,48].

Before deposition, the surface of all AM-LPBF AlSi10Mg specimens (Figures $1 \mathrm{~d}$ and $2 \mathrm{c}-\mathrm{e}$ ) was etched at room temperature for $1 \mathrm{~min}$ in a $\mathrm{NH}_{4} \mathrm{~F} / \mathrm{HF} /$ Ethylene glycol solution removing surface oxides. Next, six disk-shaped specimens were silver-plated by electroless deposition, while six more disk-shaped specimens were coated by an ultra-thin silane layer (e.g., "silanized") (functionalization step, Figure 3a,b). This "silanization" process was conducted at $70{ }^{\circ} \mathrm{C}$ for $3 \mathrm{~h}$ in $1 \%$ 3-aminopropyl-trimethoxysilane (TAPOS)/ethanol solution [21]. This process, also known as SAM, creates an ultra-thin stable, uniform, and transparent nano-scale thickness film, improving the adhesion of the Ag layer to the AlSi10Mg substrate. The SAM's molecules contain a functional group [52] and chemically bind to the 3D-printed surface [53], consequently yielding good adhesion [54] of the deposited electroless silver to the substrate. The surface of all twelve specimens was activated for $1 \mathrm{~min}$ in a Pd-citrate bath ( $\mathrm{pH} 2)$ at room temperature (Figure 3c,d), forming metal catalytic seeds on the surface and initiating the electroless deposition process. The specimens were washed in deionized (DI) water after each step of the coating process (Figure 3). The silver was deposited for 3, 5, 7, and $10 \mathrm{~min}$. After silver deposition, the coated samples were heated in an air-oven (MRC Laboratory Instruments, Holon, Israel) for $30 \mathrm{~min}$ at 110 ${ }^{\circ} \mathrm{C}[42]$.

A darkening process was applied to the silver coated disk-shaped specimens as well as to the silver coated 3D-printed coin replica specimens; this was done in order to emulate the appearance of ancient items. For that purpose, the coated samples were treated in saturated $\mathrm{I}_{2}$ / ethanol solution for $5 \mathrm{~min}$ at room temperature, and they were then washed in ethanol to eliminate unreacted iodine. Following the darkening process, the samples were air dried at room temperature and finally were polished with a flannel cloth [42].

This electroless silver plating bath and process were compared to a commercial 99.9 wt.\% pure Ag coating (Interplate Ltd., Bnei Brak, Israel) produced from a semi-bright cyanide bath. The silver plating using the commercial bath was executed on a $\approx 9.3 \mu \mathrm{m}$ nickel-phosphorus (Ni-P) interlayer containing $10 \mathrm{wt} . \%$ phosphorus. The commercial 
processes ended with an air-oven heat treatment at $180{ }^{\circ} \mathrm{C}$ for $30 \mathrm{~min}$. Limited information is presented here regarding the commercial electroless silver plating process due to commercial confidentiality [42].

\subsection{Gold Electroless Plating on AM-LPBF AlSi10Mg}

A laboratory-developed process for gold electroless deposition (Figure 3, Tables 3 and 4) was produced by Inberg et al. 2020 [43] at TAU. The coating was executed at $80-85{ }^{\circ} \mathrm{C}$ from a solution of a dicyanoaurate complex of gold and hypophosphite as a reducing agent (Table 4). This bath composition was already published by Krusenstern 1974 [55], yet it has never been applied on 3D-printed AlSi10Mg objects. Since the AlSi10Mg substrate is covered with native oxide film (Figure 3a), prior to the gold deposition, the surfaces of all the disk-shaped specimens were cleaned and etched. For this purpose, the specimens' surface was ultrasonically treated for $10 \mathrm{~min}$ at room temperature in a sodium dodecyl sulfate (SDS) solution (Figure 3b), and the weight of the specimens was reduced by about $0.001 \mathrm{~g}$. The sensitization stage (Figure 3c) was performed at room temperature for 2 min, followed by palladium activation in a Pd-citrate bath [22] for 1 min (Figure 3d), which was performed also at room temperature. The Pd activation was done in order to generate catalytic seeds (nucleation sites) on the metal surface to initiate the ELD process. To improve the gold adhesion to the AlSi10Mg substrate and prevent pitting corrosion of the coating, the gold film was deposited on an interlayer of $\approx 1 \mu \mathrm{m}$ nickel-phosphorus ( $\approx 5$ wt.\% P, Figure 3e). Ni-P plating was carried out at $95-96{ }^{\circ} \mathrm{C}$ for $1 \mathrm{~h}$ in the solution given in Table 3. The specimens were washed in DI water after each step and at the end of the process. Following the gold deposition (Figure 3f, Table 4), the specimens were heated in an air-oven at $110^{\circ} \mathrm{C}$ for $30 \mathrm{~min}$ [43].

Table 3. The electroless Ni-P solution composition ( $\mathrm{pH}=4-6)$. Adapted with permission from [43]. Copyright 2020 Copyright Springer.

\begin{tabular}{cc}
\hline Component & Concentration (M) \\
\hline Nickel(II) sulfate hexahydrate $\left(\mathrm{NiSO}_{4} \cdot 6 \mathrm{H}_{2} \mathrm{O}\right)$ & 0.114 \\
3-Na-citrate $\left(\mathrm{Na}_{3} \mathrm{C}_{6} \mathrm{H}_{5} \mathrm{O}_{7}\right)$ & 0.043 \\
Sodium hypophosphite $\left(\mathrm{NaH}_{2} \mathrm{PO}_{2}\right)$ & 0.094 \\
Sodium acetate $\left(\mathrm{NaCH}_{3} \mathrm{COO}\right)$ & 0.037 \\
\hline
\end{tabular}

Table 4. Laboratory-developed electroless gold bath composition. Adapted with permission from [43]. Copyright 2020 Copyright Springer.

\begin{tabular}{cc}
\hline Component & Concentration (M) \\
\hline Potassium dicyanoaurate $\left[\mathrm{KAu}(\mathrm{CN})_{2}\right]$ & $0.007-0.010$ \\
Ammonium chloride $\left(\mathrm{NH}_{4} \mathrm{Cl}\right)$ & $1.3-1.4$ \\
3-Na-citrate $\left(\mathrm{Na}_{3} \mathrm{C}_{6} \mathrm{H}_{5} \mathrm{O}_{7}\right)$ & $0.155-0.170$ \\
Sodium hypophosphite $\left(\mathrm{NaH}_{2} \mathrm{PO}_{2}\right)$ & $0.075-0.094$ \\
\hline
\end{tabular}

The laboratory-developed coating was compared to a commercial coating process (Interplate Ltd., Bnei Brak, Israel) where the Au film was produced from a semi-bright cyanide bath. The commercial gold plating was executed on $\mathrm{a} \approx 10 \mu \mathrm{m}$ thick $\mathrm{Ni}-\mathrm{P}(\approx 8 \mathrm{wt}$ $\% \mathrm{P}$ ) interlayer. After the gold deposition, the coated samples were heated for $30 \mathrm{~min}$ in an air-oven at $180^{\circ} \mathrm{C}$. Only partial information is presented here regarding the commercial procedure due to commercial confidentiality [43].

\subsection{Gold-Silver Electroless Plating on AM-LPBF AlSi10Mg}

A process for electroless Au-Ag plating on 3D-printed disk-shaped specimens was developed by Inberg et al. 2020 (Figure 3) [48]. Prior to the deposition process, the oxide film (Figure 3a) that covered the AlSi10Mg surface was ultrasonically cleaned and etched for $10 \mathrm{~min}$ in a $12 \mathrm{~g} / \mathrm{L}$ SDS solution at room temperature (Figure $3 \mathrm{~b}$ ). The quality of the 
coating depends on the surface roughness, post-treatment of the AlSi10Mg substrate, and the cleaning process. The cleaning and etching steps reduced the weight of the 3D-printed specimens by about $0.001 \mathrm{~g}$. Next, a sensitization process was applied (Figure $3 \mathrm{c}$ ) at room temperature for $2 \mathrm{~min}$ in a solution of $\mathrm{SnCl}_{2} / \mathrm{HCl}\left(70 \mathrm{~g} / \mathrm{L}\right.$ of $\mathrm{SnCl}_{2}$ and $40 \mathrm{~mL} / \mathrm{L}$ of $\left.\mathrm{HCl}\right)$. Palladium activation of the surface (Figure $3 \mathrm{~d}$ ) was done in a Pd-citrate solution for 1 min at room temperature to generate metal catalytic seeds that serve as nucleation sites. An Ni-P interlayer was deposited on the AlSi10Mg specimens (Figure 3e, Table 3) to improve the adhesion of the $\mathrm{Au}-\mathrm{Ag}$ alloy to the substrate (Figure $3 \mathrm{f}$ ). The electroless Au-Ag plating (Table 5) was performed at 80 and $90^{\circ} \mathrm{C}$ and several times between 1.5 and $9 \mathrm{~min}$. The specimens were washed in DI water after each step and at the end of the $\mathrm{Au}-\mathrm{Ag}$ deposition process. Following the electrum deposition, the specimens were heated treated at $100{ }^{\circ} \mathrm{C}$ in an air-oven for $30-60 \mathrm{~min}$ [48].

Table 5. The laboratory-developed bath for Au-Ag electroless deposition $(\mathrm{KOH}, \mathrm{pH}=12)$, molar ratio $[\mathrm{Ag}] /[\mathrm{Au}]$ in solution 1:2.

\begin{tabular}{cc}
\hline Component & Concentration (M) \\
\hline Potassium dicyanoaurate $\left[\mathrm{KAu}(\mathrm{CN})_{2}\right]$ & 0.007 \\
Potassium silver cyanide $\left[\mathrm{KAg}(\mathrm{CN})_{2}\right]$ & 0.0035 \\
3-Na-citrate $\left(\mathrm{Na}_{3} \mathrm{C}_{6} \mathrm{H}_{5} \mathrm{O}_{7}\right)$ & 0.170 \\
Hydrazine hydrate $\left(\mathrm{H}_{6} \mathrm{~N}_{2} \mathrm{O}\right)$ & 0.015 \\
Polyethylene glycol $1500(\mathrm{PEG} 1500)$ & 0.0003 \\
Sodium saccharin $\left(\mathrm{C}_{7} \mathrm{H}_{4} \mathrm{NNaO}_{3} \mathrm{~S}\right)$ & 0.002 \\
\hline
\end{tabular}

\subsection{Characterization Methods}

The following characterization procedures and tests were applied to the AM-LPBF 3Dprinted AlSi10Mg disk-shaped specimens before and after $\mathrm{Ag}$, $\mathrm{Au}$, and electrum coating:

(a) The specimens were weighed in their as-printed condition, after cleaning, after etching, after coating by Ni-P interlayer, and after the final coating. The measurements were made with an analytical MRC ASB-220-C2 balance (MRC Laboratory Instruments, Holon, Israel) with a precision of $\pm 0.0001 \mathrm{~g}[42,48]$.

(b) A qualitative pilling test was performed on all coated specimens with transparent vinyl tape in order to evaluate the adhesion of the metal coatings to the printed substrate [42].

(c) The thickness of the Ni-P interlayer and the electroless deposited $\mathrm{Au}, \mathrm{Ag}$, and $\mathrm{Au}-\mathrm{Ag}$ films was measured by a calibrated high-resolution FISCHERSCOPE X-RAY XDL 230 X-ray fluorescence (XRF) instrument (Fischer Technology, Inc., Windsor, CT, USA), with an approximation error of $\pm 0.1 \mu \mathrm{m}$ [42]. Each measurement was performed in a circle of $\approx 1 \mathrm{~mm}$ in diameter for $30 \mathrm{~s}$.

(d) Average roughness ( $\mathrm{Ra}$ ) and root mean square (RMS) roughness measurements were accomplished with Alpha-Step D-500 Stylus profilometer (KLA Corporation, Milpitas, CA, USA), with vertical high-resolution profiling of $0.1 \mathrm{~nm}$. The average surface roughness was calculated considering seven to 10 measurements [42].

(e) X-ray diffraction (XRD) analysis was performed before and after electroless coating with a powder PANalytical Empyrean X-Ray Diffractometer (Malvern Panalytical Company, Malvern, UK) to determine the crystal structure and lattice constants of the coated layers. Data were collected in the common symmetrical Bragg-Brentano geometry $(\theta / \theta)$ using a $\mathrm{Cu} \mathrm{K} \alpha$ radiation (wavelength of $\lambda=1.541 \AA$ ) operating at $40 \mathrm{kV}$ and $30 \mathrm{~mA}$. Phase identification from the XRD results was done by using International Centre for Diffraction Data (ICDD) databases and Pearson's handbook with the assistance of a PowderCell program for powder pattern calculation $[48,56]$.

(f) HIROX RH-2000 digital 3D multi-focal light microscope (LM) (HIROX Company, Tokyo, Japan), equipped with different optical lenses, a high-intensity LED lighting source, and powerful 3D software, was used to characterize the specimens' general 
surface quality before and after coating and to identify microscopic discontinuities and defects $[43,57]$.

(g) Scanning electron microscopy (SEM) observation and energy-dispersive spectroscopy (EDS) analysis were performed with an ESEM FEI Quanta 200 FEG instrument (FEI Company, Hillsboro, OR, USA) in the high vacuum mode, before and after the electroless coating. An Everhart-Thonley secondary electron liquid-nitrogen-cooled $\mathrm{Si}(\mathrm{Li})$ X-ray EDS detector (Oxford Instruments Company, Abingdon, UK), calibrated with standard specimens received from the instrument manufacturer, was utilized to measure the chemical composition of the substrate and the coating. The EDS analysis provided results with an estimated error of $1 \%$ [42].

(h) Focused ion beam (FIB) technology with an accelerated high-energy gallium ions source, equipped with high-resolution SEM Helios 600 SEM/FIB dual beam (Thermo Fisher Scientific, Waltham, MA, USA), was applied in order to observe the crosssection of the silver, gold, and electrum plated specimens. Before digging into the specimen, a thin layer of platinum was deposited (voltage of $2.0 \mathrm{kV}$ and current of $2.7 \mathrm{nA}$ ) on the surface of the samples to protect the deposited films during the milling processes. The digging was performed with a high voltage of $30.0 \mathrm{kV}$ and a beam current of $21.0 \mathrm{nA}$, which was followed by etching with a $6.5 \mathrm{nA}$ beam current. The FIB's milled cut dimensions were $15 \mu \mathrm{m} \times 15 \mu \mathrm{m}$, with a depth of $\approx 7 \mu \mathrm{m}$ [42].

(i) X-ray photoelectron spectroscopy (XPS) profiling with an Al K $\alpha$ monochromatic irradiation source $(1486.6 \mathrm{eV})$ was performed to the electrum coated specimens by using 5600 Multi-Technique System (PHI Inc., Chanhassen, MN, USA) in an ultrahigh vacuum (UHV) with a base pressure of $2.5 \times 10^{-10}$ Torr. The specimens were not charged during the analysis. The outcome electrons were examined with a Spherical Capacitor Analyzer (SCA), using a $0.8 \mathrm{~mm}$ slit aperture. The sputtering was performed with a $4 \mathrm{kV} \mathrm{Ar}{ }^{+}$Ion Gun using $17 \AA /$ min sputter rate on $\mathrm{SiO}_{2} / \mathrm{Si}$ and was assumed to be approximately three times higher on $\mathrm{Au}-\mathrm{Ag}$ [48].

\section{Results}

\subsection{AM-LPBF AlSi10Mg Disk-Shaped Specimens}

The disk-shaped specimens and the coin replica specimens revealed rough and slightly porous surfaces (Figure $4 \mathrm{a}-\mathrm{c}$ ), as expected for vertical AM-LPBF AlSi10Mg surfaces $[9,12,58]$. The measured mass values of the AM-LPBF AlSi10Mg disk-shaped specimens were between 4.817 and $4.859 \mathrm{~g}$, with diameter values lying between 25.90 and $26.07 \mathrm{~mm}$. The as-printed surface roughness of the specimens was $21.23 \mu \mathrm{m}$ according to RMS and $17.03 \mu \mathrm{m}$ according to Ra measurements [42].

LM and SEM observation of the specimens revealed a rough surface morphology (Figure 2c-e). SEM-EDS analysis revealed that the AlSi10Mg disk-shaped specimens were composed of aluminum, containing $9.8 \mathrm{wt} . \%-11.3 \mathrm{wt} . \% \mathrm{Si}, \approx 2.3 \mathrm{wt} . \% \mathrm{O}$, and $0.4 \mathrm{wt} . \%-0.5$ wt.\% Mg [42].

The XRD analysis of the AlSi10Mg samples (Figure 5a) exhibited the characteristic peaks of $\mathrm{Al}$ and $\mathrm{Si}$ (Al-Si eutectic structure), yet since the content of $\mathrm{Mg}$ is relatively low (less than $0.5 \mathrm{wt} . \%$ ), $\mathrm{Mg}$ or its compound peaks were not detected [42]. 


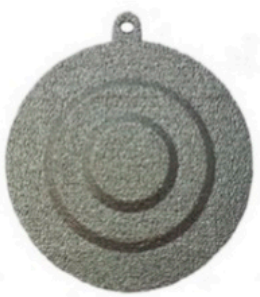

(a)

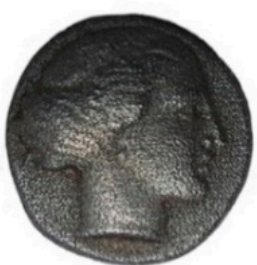

(b)

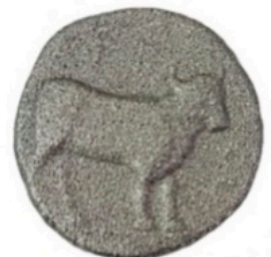

(c)

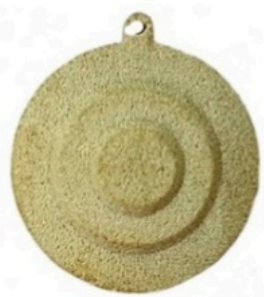

(d)

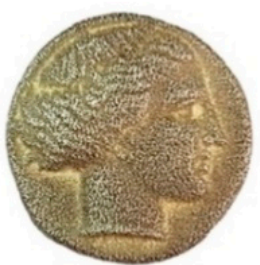

(e)

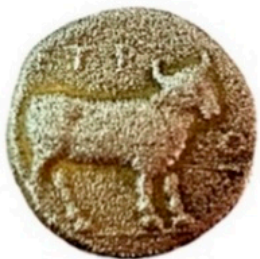

(f)

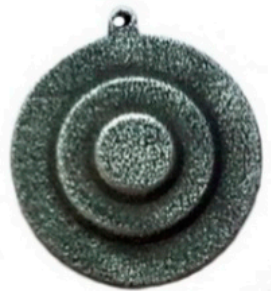

(g)

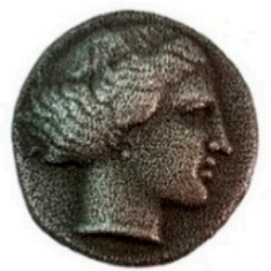

(h)

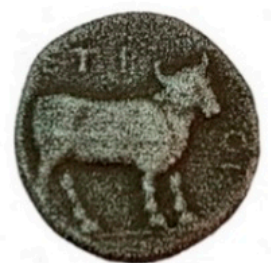

(i)

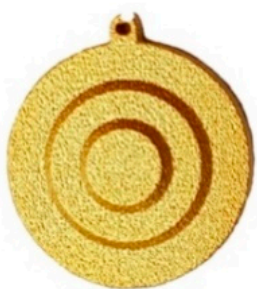

(j)

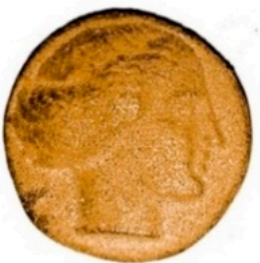

(k)

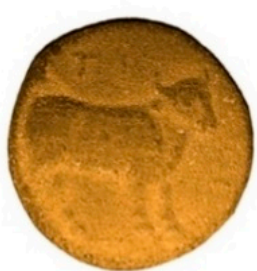

(l)

Figure 4. The experimental specimens before and after coating: (a) the as-printed AM-LPBF AlSi10Mg disk-shaped reference; $(\mathbf{b}, \mathbf{c})$ the as-printed AM-LPBF AlSi10Mg coin replica (obverse and reverse, respectively); (d) the as-printed disk-shaped specimen coated with Ag; (e,f) the coin replica coated with Ag; (g) the disk specimen coated with Ag after darkening process; $(\mathbf{h}, \mathbf{i})$ the coin replica coated with Ag after darkening process; (j) the disk-shaped specimen coated with $\mathrm{Au}$; and $(\mathbf{k}, \mathbf{l})$ the coin replica coated with Au.

\subsection{Silver Electroless Plating on AM-LPBF AlSi10Mg Disk-Shaped Specimens}

The disk-shaped and coin replica specimens coated with the laboratory-developed silver film exhibited a relatively uniform bright but not shiny surface, with rough topography (Figure $4 \mathrm{~d}-\mathrm{f}$ ). Yet the surface of the silver coated samples was less rough than the bare surface. The measured mass values of the silver coated specimens were between 4.838 and $4.890 \mathrm{~g}$. The mass of the silver deposited layer was measured to be $0.002 \mathrm{~g}$ for the $3 \mathrm{~min}$ coating and $0.066 \mathrm{~g}$ for the $10 \mathrm{~min}$ coating. The qualitative pilling test examination of the silver-coated samples (with and without SAM) revealed a high-quality coating. A satisfactory appearance of authentic ancient objects was achieved for both silver-coated disk-shaped and coin replica specimens after the darkening process (Figure 4g-i) [42].

The XRD analysis of the silver-coated surface (Figure $5 \mathrm{~b}$, Graph 1 ) revealed characteristic peaks of the $\mathrm{Ag}, \mathrm{Al}$, and $\mathrm{Si}$, as expected of the AlSi10Mg surface coated with $\approx 1 \mu \mathrm{m}$ silver film. The presence of characteristic peaks of aluminum and silicon probably results from the existence of voids and cavities in the silver film [42].

The thickness of the silver coating with silanization treatment was $1.06 \pm 0.12 \mu \mathrm{m}$ and without silanization was $1.16 \pm 0.16 \mu \mathrm{m}$ (XRF results, Figure 6a). The average RMS and Ra surface roughness values (measured by profilometer) were both reduced after coating (Figure 6b). The SAM layer had no noteworthy effect on the Ag layer deposition rate allowed by the Pd-Ag binding energy [23,42]. SEM observation of the coated surface revealed a rough surface morphology (Figure $7 a, b)$. The roughness values were reduced when the deposition time was increased (Figure 6b). 

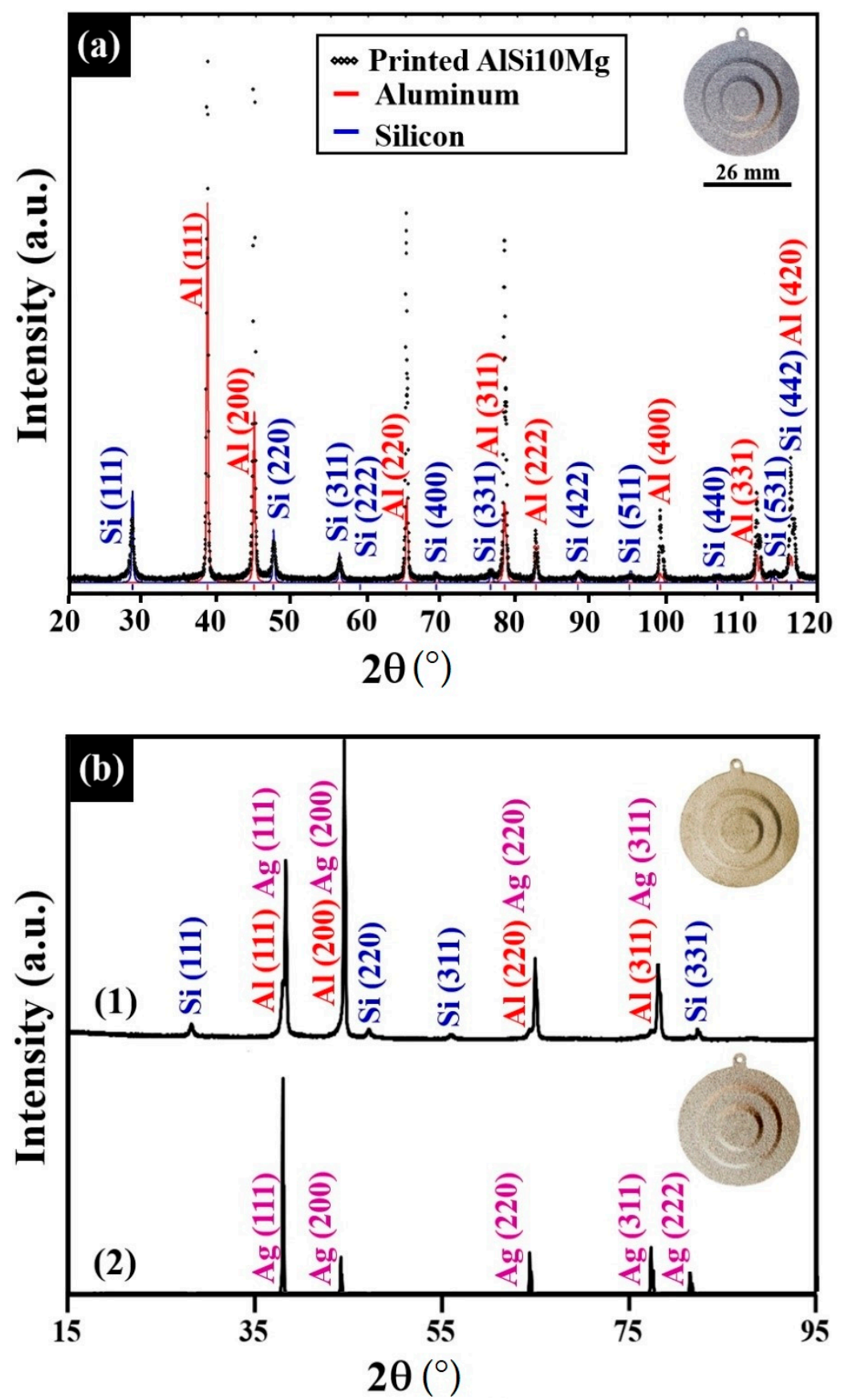

Figure 5. XRD patterns of the: (a) as-printed AM-LPBF AlSi10Mg substrate; (b) AlSi10Mg diskshaped specimens coated with laboratory-developed silver (Ag thickness of $\approx 1 \mu \mathrm{m}$, Graph 1 ) and commercial coating (Ag thickness $\approx 16 \mu \mathrm{m}$, Graph 2). 

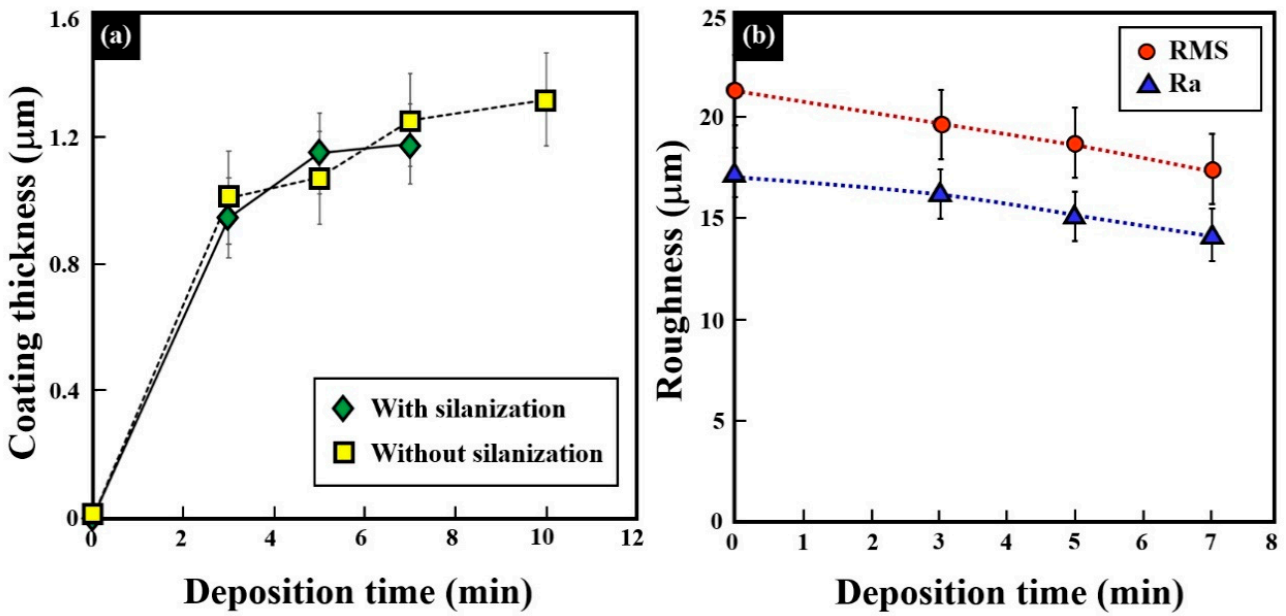

Figure 6. The laboratory-developed silver coating on top of AM-LPBF AlSi10Mg substrate: (a) film thickness as a function of deposition time with and without silanization; and (b) RMS and Ra surface roughness without silanization (measured by profilometer).

SEM-EDS analysis of the coated disk-shaped specimens revealed that the silver layer contains up to $2.1 \mathrm{wt}$. $\%$ O, up to $1.8 \mathrm{wt}$ \% $\mathrm{C}$, and $0.7 \mathrm{wt}$ \% $\mathrm{Al}$. FIB-SEM examination of the 3 min silver coated specimen's cross-section (Figure 8a,b), revealed that the silver layer thickness varies between 0.5 and $1.0 \mu \mathrm{m}$. The silver film showed a wavy topography behavior with some grooves, which were caused by the high roughness of the AlSi10Mg substrate and the absence of an Ni-P interlayer [42].
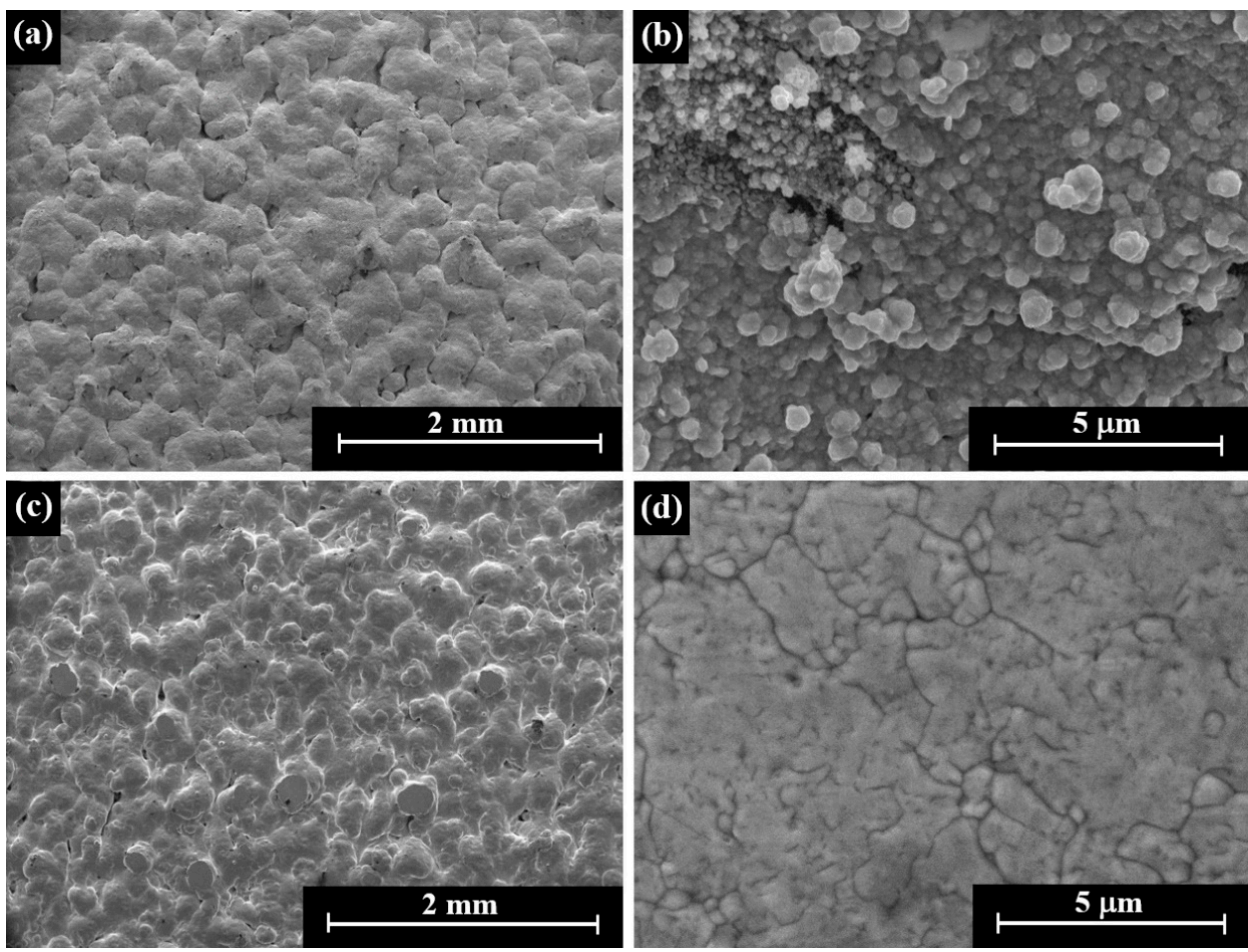

Figure 7. SEM images of the AM-LPBF AlSi10Mg disk-shaped specimens after silver electroless plating: $(\mathbf{a}, \mathbf{b})$ the external surface of the laboratory-developed Ag coated specimen; and (c,d) the external surface of the commercial Ag coated specimen.

The commercial silver-coated disk-shaped specimens exhibited uniform shiny metal surfaces with rough topography; however, the coated surface roughness was smaller than that of the as-printed surface. The qualitative pilling test of the commercial silver coating 
also confirmed good adhesion. The measured thickness (using the XRF technique) of the commercial coating was between 14.80 and $17.00 \mu \mathrm{m}$. The XRD analysis of the commercial silver film showed characteristic peaks of the Ag (Figure 5b, Graph 2). SEM examination of the coated specimens revealed a surface morphology practically similar to the amorphous materials (Figure 7c,d). EDS analysis of the commercial coating shows that it was composed of 100 wt. $\%$ Ag [42].

\subsection{Gold Electroless Plating on AM-LPBF AlSi10Mg Disk-Shaped Specimens}

The disk-shaped specimens and the coin replica specimens coated with the laboratorydeveloped gold film revealed uniform bright and shiny surfaces, with rough topography (Figure $4 \mathrm{j}-1$ ). Yet the surface of the coated specimens was slightly less rough than the uncoated surface [43].

The XRD analysis of the laboratory-developed specimen (Figure 9a) revealed that it was composed of crystalline $\mathrm{Au}$ and partially quasi-amorphous Ni. Characteristic peaks of the $\mathrm{Al}$ and $\mathrm{Si}$ were also detected [43].
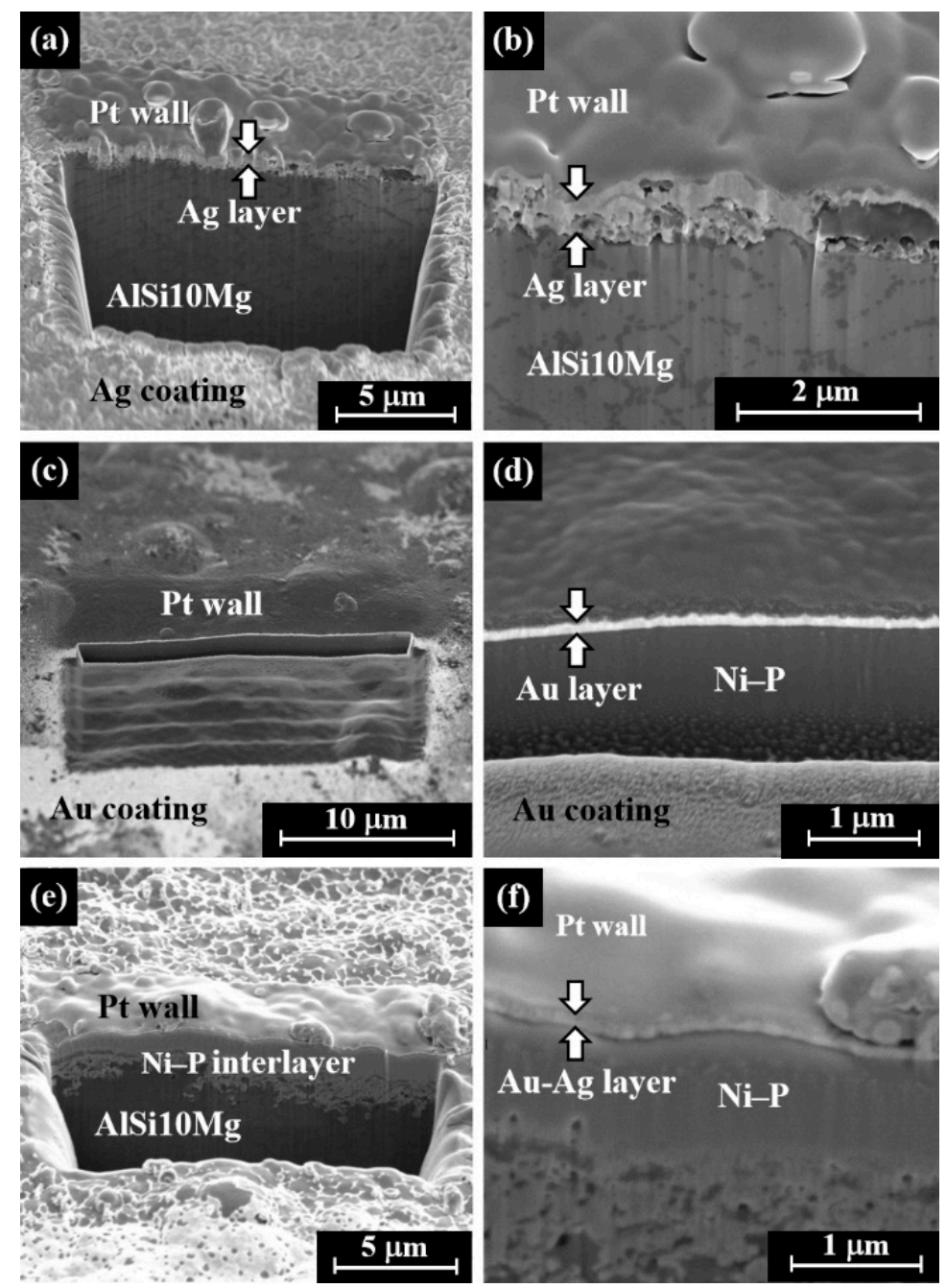

Figure 8. SEM images of the laboratory-plated AlSi10Mg sample following selective material milling by the focused ion beam (FIB) technology starting from the specimen surface: $(\mathbf{a}, \mathbf{b})$ cross-section of the Ag-plated sample, showing the hole cut by FIB, the Pt wall behind the hole, and the printed substrate with the Ag layer on top; (c,d) a cross-section of the Au-plated sample, showing the hole cut by FIB, the Pt wall, the substrate, the $\approx 1 \mu \mathrm{m} \mathrm{Ni}-\mathrm{P}(\approx 5 \mathrm{wt} . \% \mathrm{P})$ layer, and the Au layer on top (white layer); (e,f) cross-section of the electrum-plated sample, showing the hole cut by FIB, the $\mathrm{Pt}$ wall, the substrate, the Ni-P layer, and the Au-Ag layer on top. 

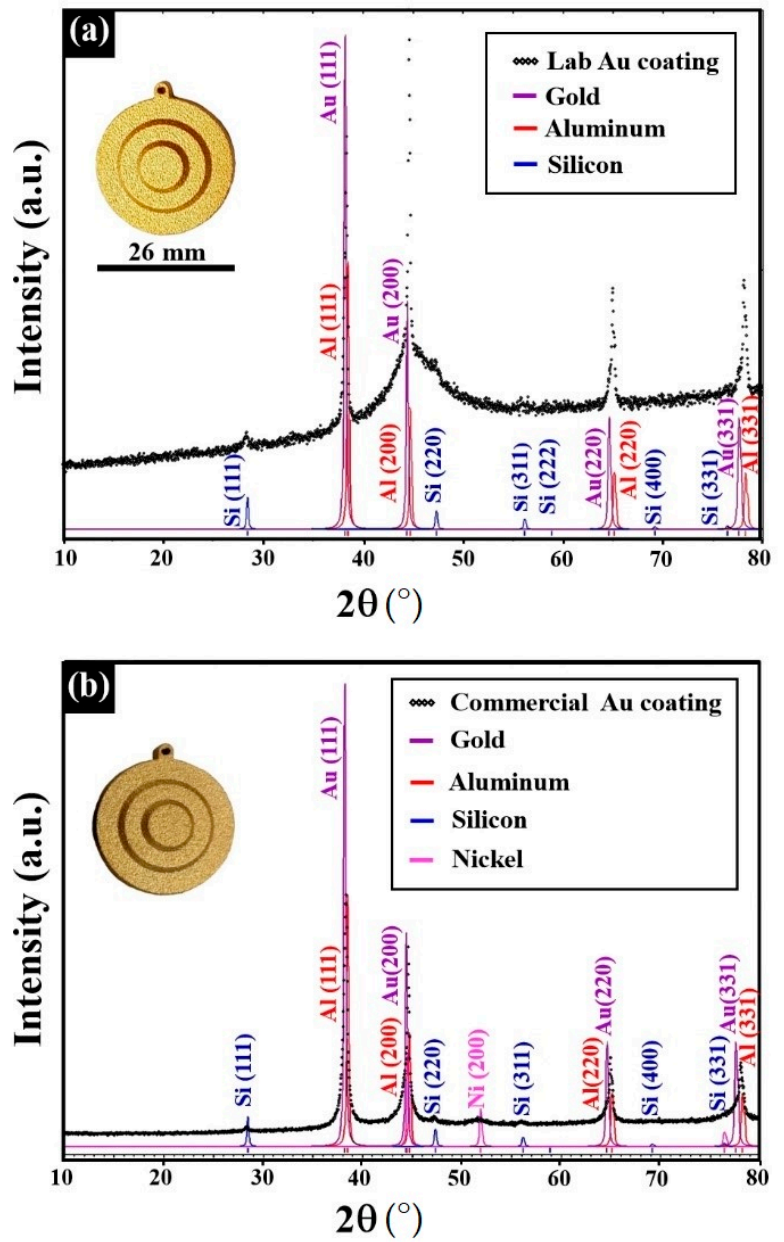

Figure 9. XRD patterns of the AlSi10Mg printed disk-shaped specimens electroless gold plated, the dark line represents the current experimental results: (a) laboratory-developed Au coating and (b) commercial Au-plated coating.

The thickness of the Au film according to the XRF measurements was $0.07 \mu \mathrm{m}$ for the $3 \mathrm{~min}$ deposition and $0.70 \mu \mathrm{m}$ for the $10 \mathrm{~min}$ deposition (Figure 10a). The mass values of the coated specimens including the Ni-P and gold layers were between 4.888 and 4.939 $\mathrm{g}$. The mass of the deposited gold layer was $0.024 \mathrm{~g}$ for the $1 \mathrm{~min}$ coating and $0.079 \mathrm{~g}$ for the 5 min coating. The average RMS and Ra surface roughness were both slightly reduced after the coating process (Figure 10b), which may be attributed to the Ni-P interlayer (with thickness of $1 \mu \mathrm{m})$. Moreover, the roughness values monotonically decrease with deposition time (Figure 10b). Nevertheless, it is important to note that the thickness of the Ni-P interlayer and the gold film are both well below the average surface roughness. Therefore, the surface appearance of the AM-LPBF AlSi10Mg substrate on the macroscopic level is quite close to that of the laboratory-developed Au coated specimens (Figure 11a,b) [43]. 

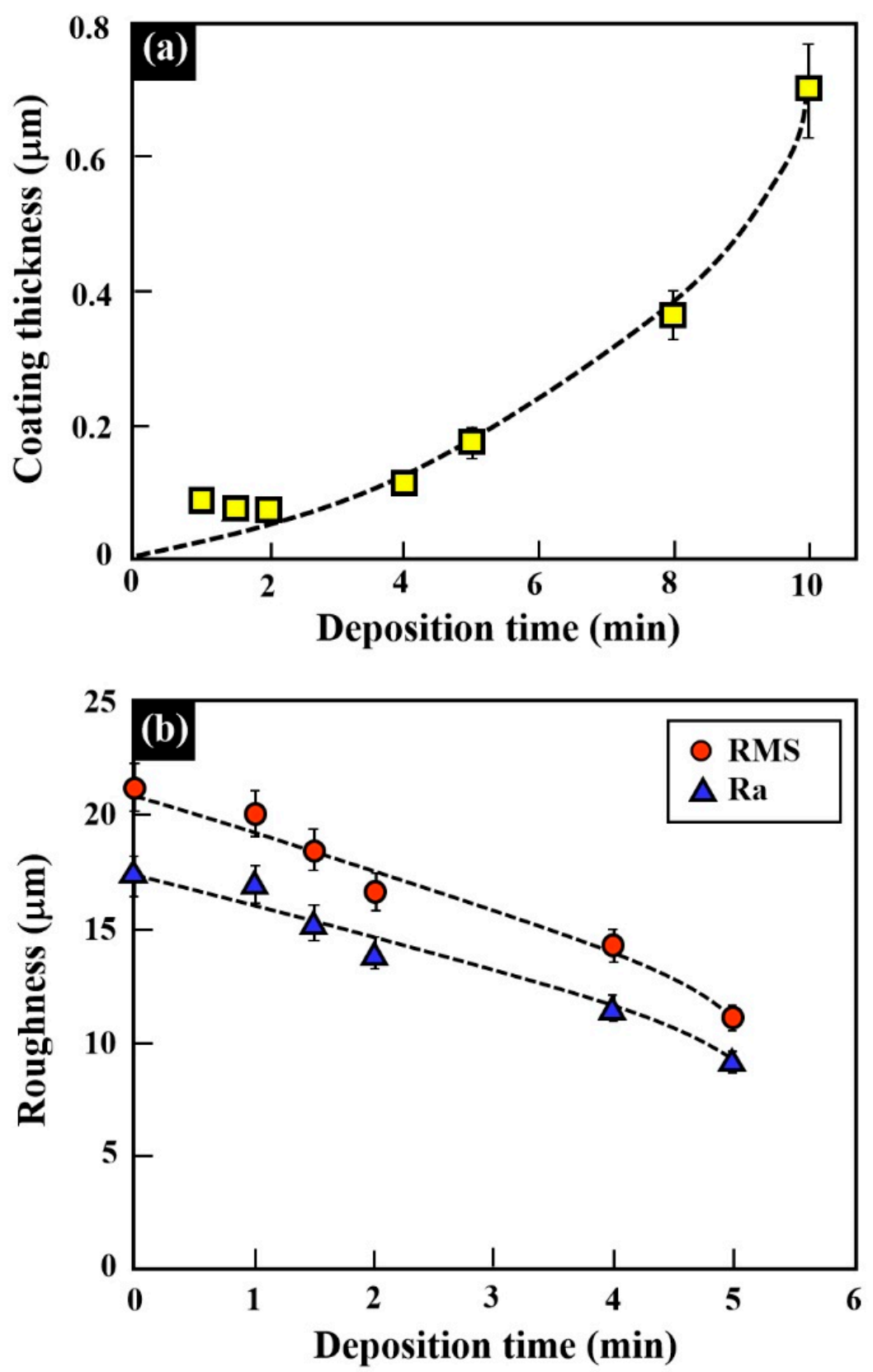

Figure 10. The gold coating on top of AM-LPBF AlSi10Mg printed substrate: (a) film thickness as the function of time; and (b) the RMS and Ra roughness (measured by profilometer).

The deposited gold was too thin to allow the use of conventional metallographic cross-section methods. Therefore, a cross-section was created by FIB technology, enabling FIB-SEM examination of a 5 min gold coated specimen (Figure 8c,d). A relatively uniform film of gold coating was observed, with thickness varying between 0.09 and $0.13 \mu \mathrm{m}$. At the microscopic level, this uniform gold film does not follow the wavy topography of the AM-LPBF AlSi10Mg substrate. The AM-LPBF AlSi10Mg surface roughness was relatively reduced by the addition of the $\mathrm{Ni}-\mathrm{P}$ interlayer as expected [32]. The FIB-SEM thickness measurements were in good agreement with the XRF technique measurements. For instance, the XRF measurements of the 5 min gold deposited specimen gave a measured film thickness of $0.17 \mu \mathrm{m}[43]$. 

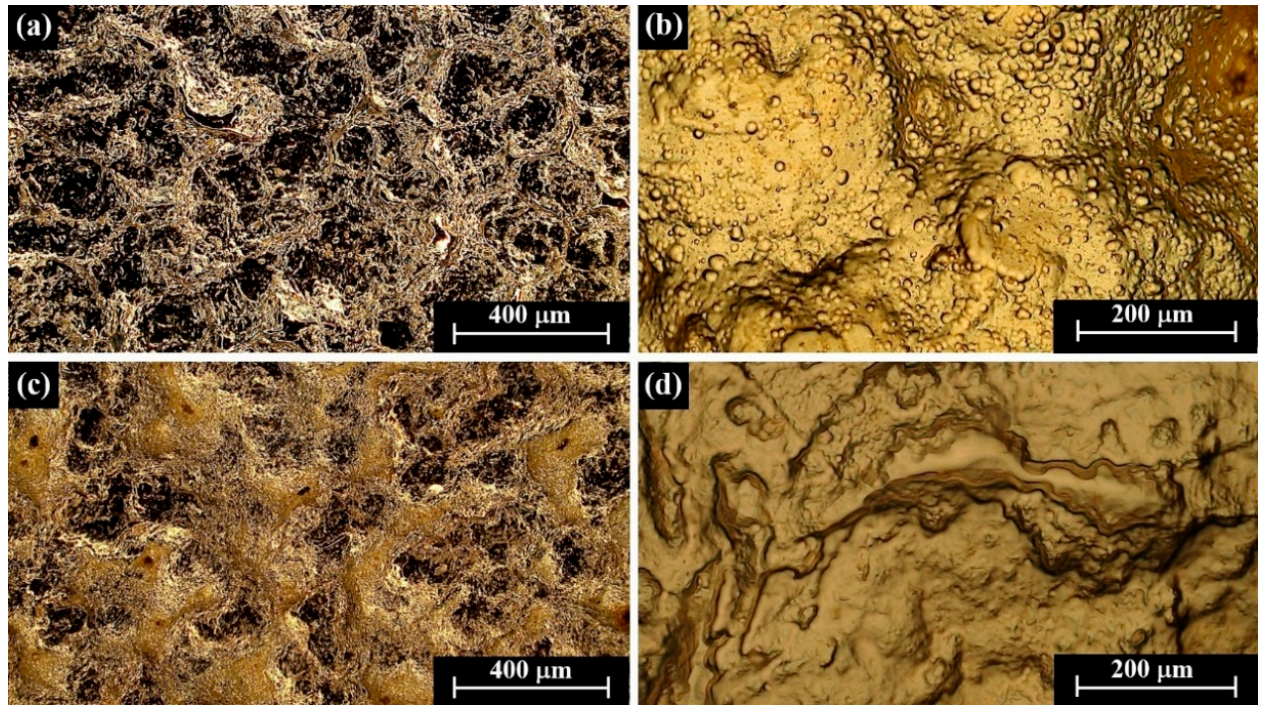

Figure 11. Multi-focal optical light microscope (LM) images of the AM-LPBF AlSi10Mg disk-shaped specimens: (a,b) laboratory-developed Au coating; and (c,d) commercial Au coating.

The commercial gold coated disk-shaped specimens displayed relatively uniform shiny metal surfaces with rough topography (Figure 11a,b). Yet the coated surface was less rough than the AM-LPBF AlSi10Mg surface. The qualitative pilling test of the commercial gold film also shows good adhesion. The measured thickness of the commercial coating was $0.50 \pm 0.02 \mu \mathrm{m}$ according to XRF measurements. The XRD analysis of the commercial gold film revealed that the coated surface is composed of crystalline Au and nanocrystalline $\mathrm{Ni}-\mathrm{P}$ (Figure 9b). Asymmetric peak profiles were observed by Inberg et al. 2020, owing to overlapping of $\mathrm{Au}$ and $\mathrm{Al}$ Bragg reflections. Naturally, beneath the coatings, the substrate was composed of $\mathrm{Al}$ and $\mathrm{Si}$ crystalline phases [43].

\subsection{Gold-Silver Electroless Plating on AM-LPBF AlSi10Mg Disk-Shaped Specimens}

Based on the visual testing examination, the Au-Ag coated AM-LPBF AlSi10Mg diskshaped specimens exhibited uniform shiny metal surfaces with rough topography (Figures 12 and 13). Yet the $\mathrm{Au}-\mathrm{Ag}$ coated specimens were somewhat less rough than the uncoated ones. It is noteworthy that the specimens deposited with 1:1 Ag/ $\mathrm{Au}$ molar ratio of solution (Figure $12 \mathrm{~b}-\mathrm{d}$ ) and $1: 2 \mathrm{Ag} / \mathrm{Au}$ molar ratio of solution at $80^{\circ} \mathrm{C}$ (Figure 12e-h) display a shiny gray-silver color coating. Yet specimens produced with 1:2 Ag/ Au molar ratio of solution at $90^{\circ} \mathrm{C}$ (Figure $12 \mathrm{i}-1$ ) exhibited a shiny yellow-gold color coating. The qualitative pilling test of the Au-Ag coated specimens revealed high-quality adhesion [48]. LM examinations of the electrum coated specimens exposed rough topography, but it was slightly less than that of the as-printed surface, with rather uniform shiny metal surfaces (Figure 13), whereas the films deposited at $80^{\circ} \mathrm{C}$ were shiny gray-silver with a slight yellow tone (Figure 13c-f), and the film deposited at $90^{\circ} \mathrm{C}$ was shiny yellow-gold (Figure 13g,h). 


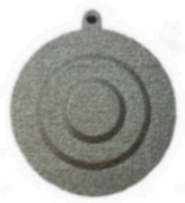

(a)

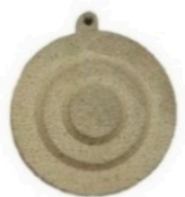

(e)

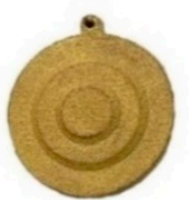

(i)

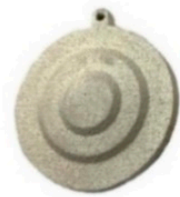

(b)

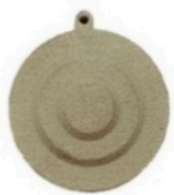

(f)

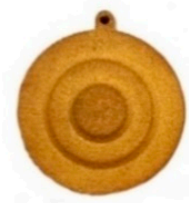

(j)

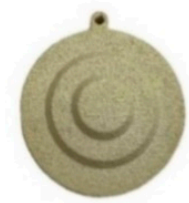

(c)

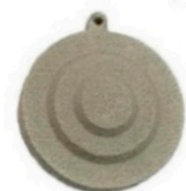

(g)

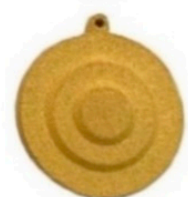

(k)

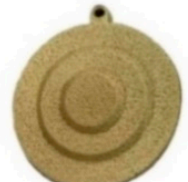

(d)

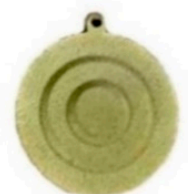

(h)

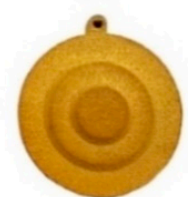

(I)

Figure 12. The AM-LPBF AlSi10Mg disk-shaped specimens, coated with electroless Au-Ag film: (a) as-printed reference specimen; (b-d) specimens coated with 1:1 Ag/ Au molar ratio of solution at $80^{\circ} \mathrm{C} ;(\mathbf{e}-\mathbf{h})$ coated with 1:2 $\mathrm{Ag} / \mathrm{Au}$ molar ratio of solution at $80^{\circ} \mathrm{C}$; and (i-1) specimens coated with 1:2 Ag/ Au molar ratio at $90^{\circ} \mathrm{C}$.
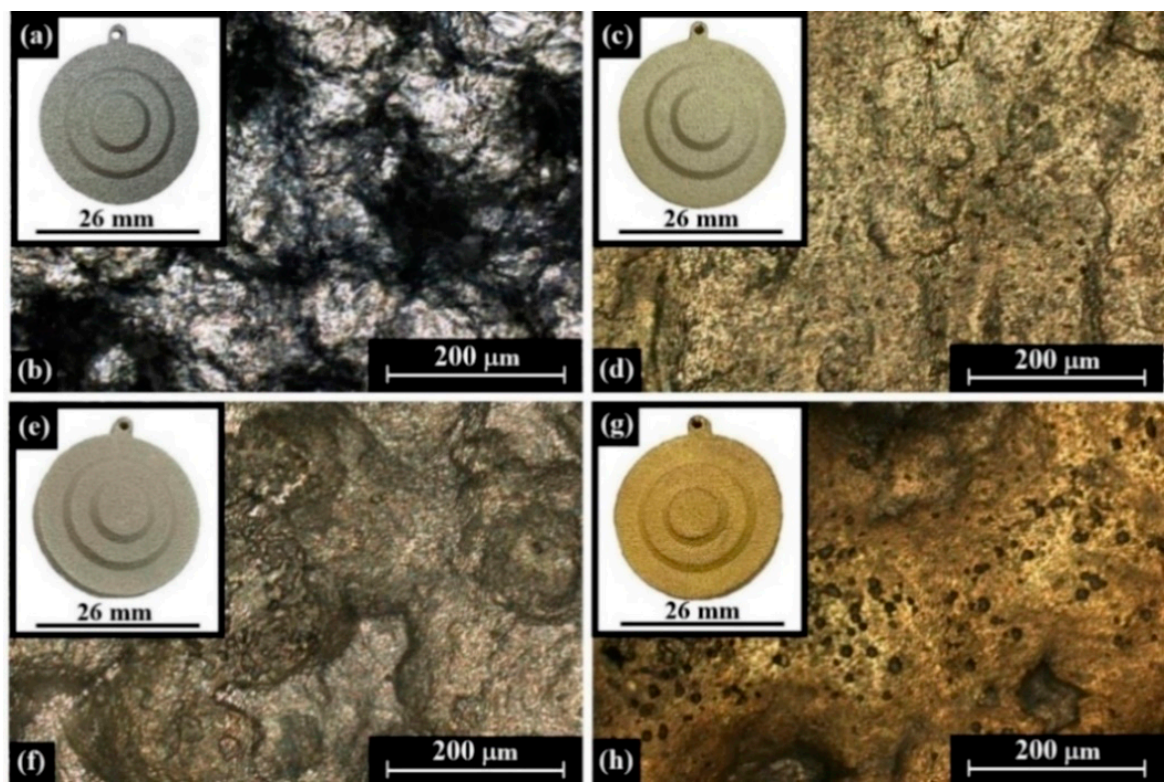

Figure 13. Optical images of the AM-LPBF AlSi10Mg disk-shaped specimens' surface: (a,b) asprinted sample; $(\mathbf{c}, \mathbf{d})$ covered with electroless electrum layer, produced with 1:1 $\mathrm{Ag} / \mathrm{Au}$ molar ratio of solution at $80^{\circ} \mathrm{C} ;(\mathbf{e}, \mathbf{f})$ covered with electroless electrum layer, produced with 1:2 Ag/ $\mathrm{Au}$ molar ratio of solution at $80^{\circ} \mathrm{C}$; and $(\mathbf{g}, \mathbf{h})$ covered with electroless electrum layer, produced with 1:2 $\mathrm{Ag} / \mathrm{Au}$ molar ratio of solution at $90^{\circ} \mathrm{C}$.

The XRD analysis results of the laboratory-developed electrum coatings revealed that they were composed of an Au-Ag crystalline solid-solution phase, with lattice parameter between $4.076 \pm 0.001 \AA$ and $4.080 \pm 0.001 \AA$, depending on molar ratio of the metals in the solution and the temperature of the coating process; underneath the $\mathrm{Au}-\mathrm{Ag}$ film, a quasiamorphous or a mixed quasi-amorphous and nanocrystalline Ni-P interlayer (Figure 14, Table 6) was found. It should be noted that the Ni-P interlayer of the samples deposited at $80{ }^{\circ} \mathrm{C}$ displays a disordered atomic-scale quasi-amorphous structure, whereas the interlayer on samples deposited at $90{ }^{\circ} \mathrm{C}$ exhibits a mix of a quasi-amorphous and a nanocrystalline 
structure. Since the deposition process was performed below $100{ }^{\circ} \mathrm{C}$, the crystallization around nucleation centers occurred at a low rate, allowing the growth of quasi-amorphous or mixed Ni-P phases [48].
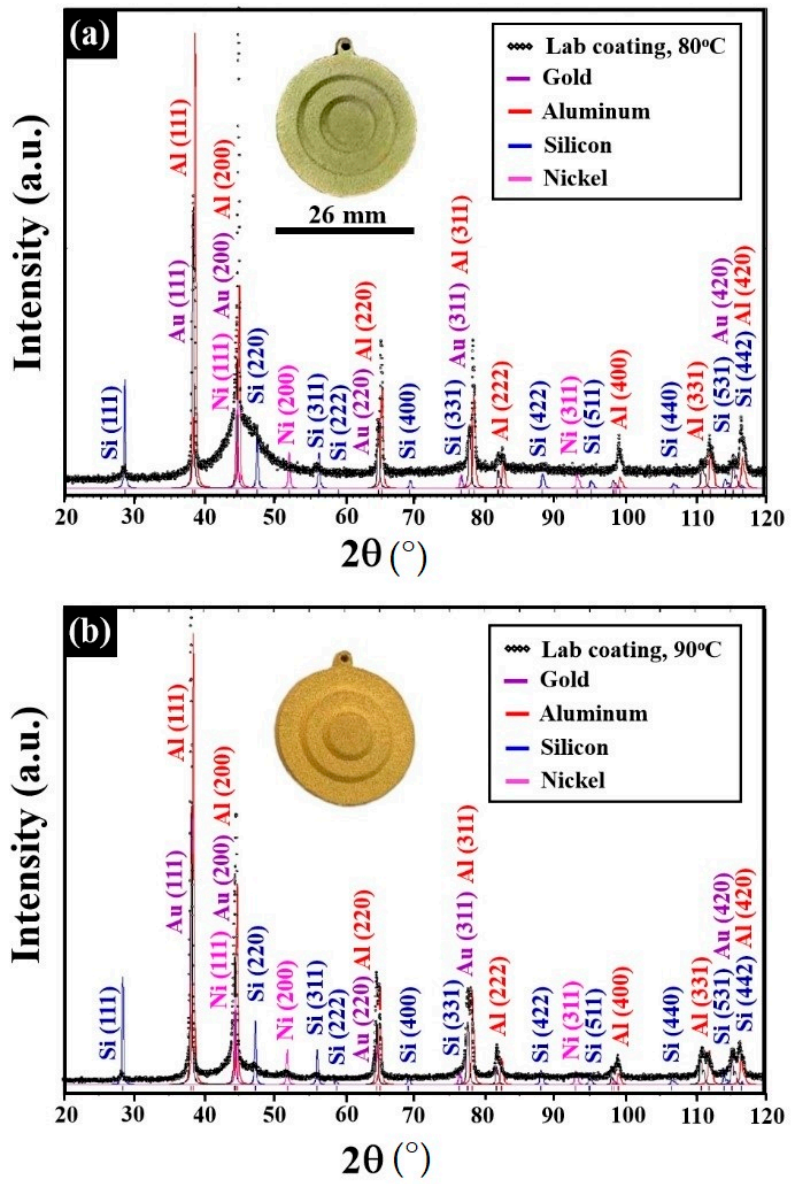

Figure 14. XRD patterns of the AlSi10Mg disk-shaped specimens electrum-plated with laboratorydeveloped electroless coating; the dark line represents the current experimental results: (a) produced with 1:2 Ag/ Au molar ratio of solution at $80^{\circ} \mathrm{C}$; and (b) produced with 1:2 $\mathrm{Ag} / \mathrm{Au}$ molar ratio of solution at $90^{\circ} \mathrm{C}$.

Table 6. Phase identification and electrum lattice parameter for the Au-Ag coated specimens.

\begin{tabular}{|c|c|c|c|c|}
\hline Specimen & $\begin{array}{l}\text { Lattice Parameter } \\
\text { (Å) }\end{array}$ & $\begin{array}{c}\text { Characteristics of } \\
\text { the Au-Ag } \\
\text { Coating }\end{array}$ & $\begin{array}{c}\text { Characteristics of } \\
\text { the Ni-P } \\
\text { Interlayer }\end{array}$ & $\begin{array}{c}\text { Characteristics } \\
\text { of the } \\
\text { Substrate }\end{array}$ \\
\hline $\begin{array}{c}1: 1 \mathrm{Ag} / \mathrm{Au} \text { molar ratio } \\
\text { at } 80^{\circ} \mathrm{C}\end{array}$ & $4.080( \pm 0.001)$ & \multirow{2}{*}{$\begin{array}{l}\text { Rich in Ag, } \\
\text { solid-solution } \\
\text { crystalline phase }\end{array}$} & \multirow[t]{2}{*}{ Quasi-amorphous } & \multirow{3}{*}{$\begin{array}{c}\text { Major } \\
\text { crystalline } \\
\text { phase AlMinor } \\
\text { crystalline } \\
\text { phase Si }\end{array}$} \\
\hline $\begin{array}{c}\text { 1:2 Ag/ Au molar ratio } \\
\text { at } 80^{\circ} \mathrm{C}\end{array}$ & $4.079( \pm 0.001)$ & & & \\
\hline $\begin{array}{c}1: 2 \mathrm{Ag} / \mathrm{Au} \text { molar ratio } \\
\text { at } 90^{\circ} \mathrm{C}\end{array}$ & $4.076( \pm 0.001)$ & $\begin{array}{l}\text { Rich in } \mathrm{Au}, \\
\text { solid-solution } \\
\text { crystalline phase }\end{array}$ & $\begin{array}{c}\text { Mix of } \\
\text { quasi-amorphous } \\
\text { and } \\
\text { nanocrystalline }\end{array}$ & \\
\hline
\end{tabular}

The total mass values of the Ni-P interlayer and the electrum deposited films were between 0.012 and $0.044 \mathrm{~g}$. The mass of the Au-Ag films increases substantially during the first 3-4 min of the deposition process (Figure 15a). A very thin Au-Ag film, with thickness up to $0.363 \mu \mathrm{m}$, was measured by an XRF instrument (Figure 15b). The measured thickness of the Ni-P interlayer was between 2.3 and $5.7 \mu \mathrm{m}$ [48]. 

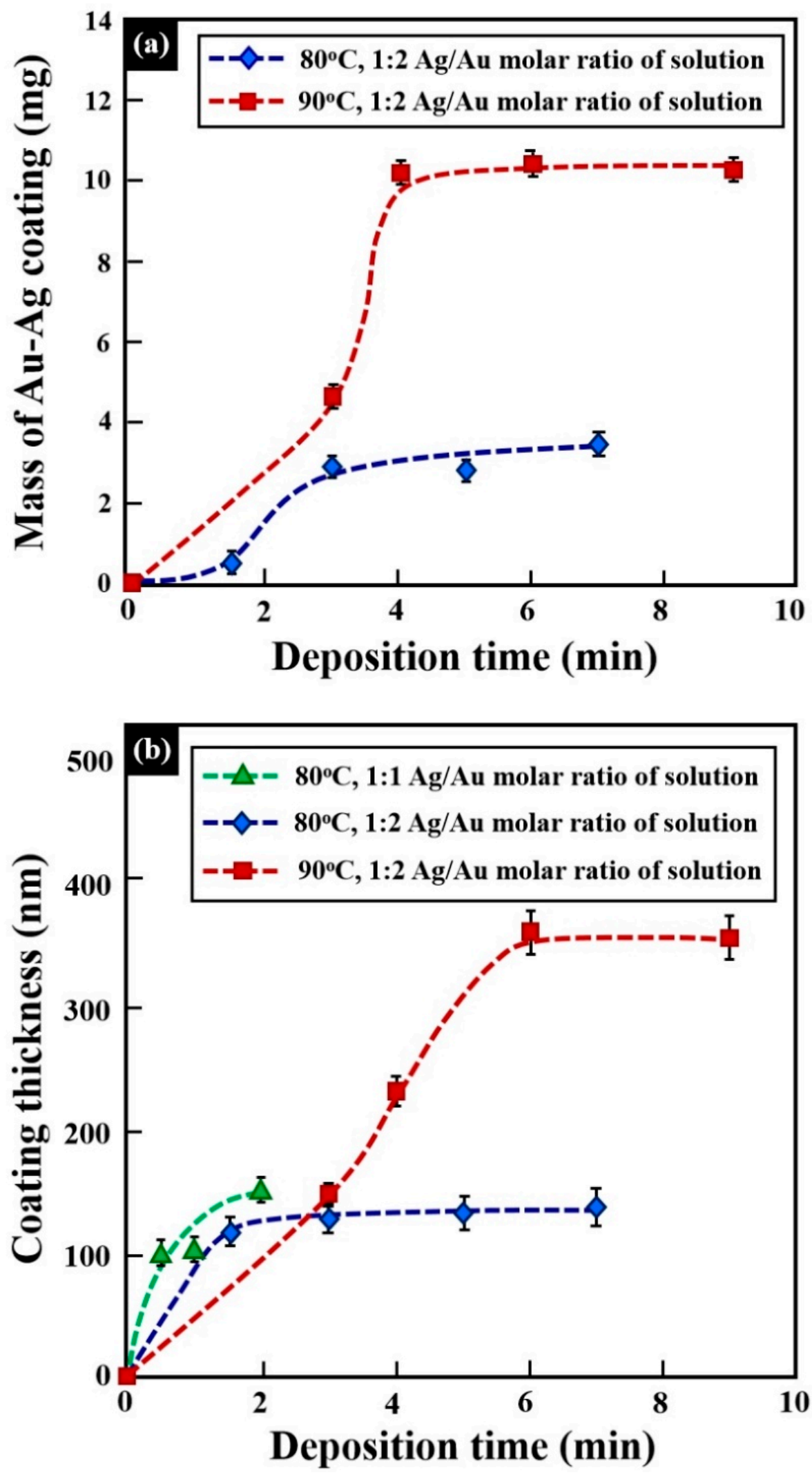

Figure 15. Laboratory-developed electrum (Au-Ag) coatings deposited at 80 and $90^{\circ} \mathrm{C}$ : (a) mass of the coating after eliminating the Ni-P interlayer contribution vs. deposition time; and (b) thickness of the coating film (measured by X-ray fluorescence instrument) vs. deposition time. 
The RMS and Ra surface roughness values of the Au-Ag coated specimens were somewhat lower than the roughness of as received AM-LPBF AlSi10Mg surface (Figure 16). This may be explained by the surface smoothing of the as-printed surface by the Ni-P interlayer. Moreover, when the deposition time was increased, the RMS and Ra roughness values were reduced (Figure 16) [48].

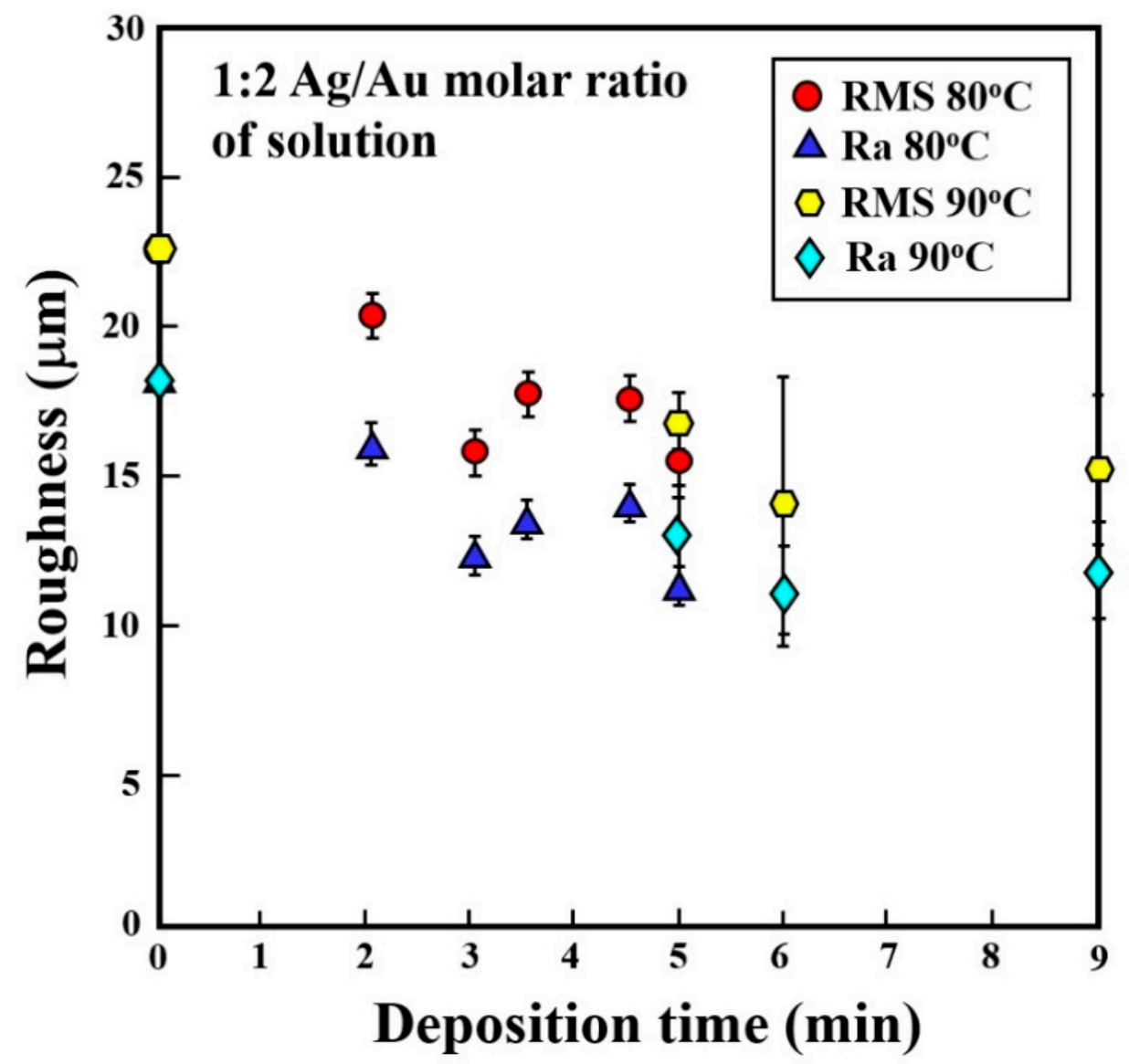

Figure 16. The root mean square (RMS) and roughness (Ra) roughness of the AM-LPBF AlSi10Mg disk-shaped specimens coated with electrum film (measured by profilometer) vs. deposition time.

The $\mathrm{Au}-\mathrm{Ag}$ coating deposited from a solution with $1: 1 \mathrm{Ag} / \mathrm{Au}$ molar ratio at $80{ }^{\circ} \mathrm{C}$ was characterized by the FIB-SEM technique (Figure 8e-f). The relatively uniform electrum film was achieved due to the Ni-P interlayer, with average Au-Ag thickness of $\approx 0.1 \mu \mathrm{m} \mathrm{[48].}$

Based on the XPS profile analysis (Figure 17), the thickness of the Au-Ag layer after 3 min deposition at 80 and $90{ }^{\circ} \mathrm{C}$ was $\approx 0.1$ and $0.25 \mu \mathrm{m}$, respectively. For electrum deposition from a 1:2 Ag/ $\mathrm{Au}$ molar ratio solution, silver was dominant at $80{ }^{\circ} \mathrm{C}$ in $\mathrm{Au}-\mathrm{Ag}$ film, at the beginning of the deposition process and at $90^{\circ} \mathrm{C}$, gold was first identified on the interface [48]. 

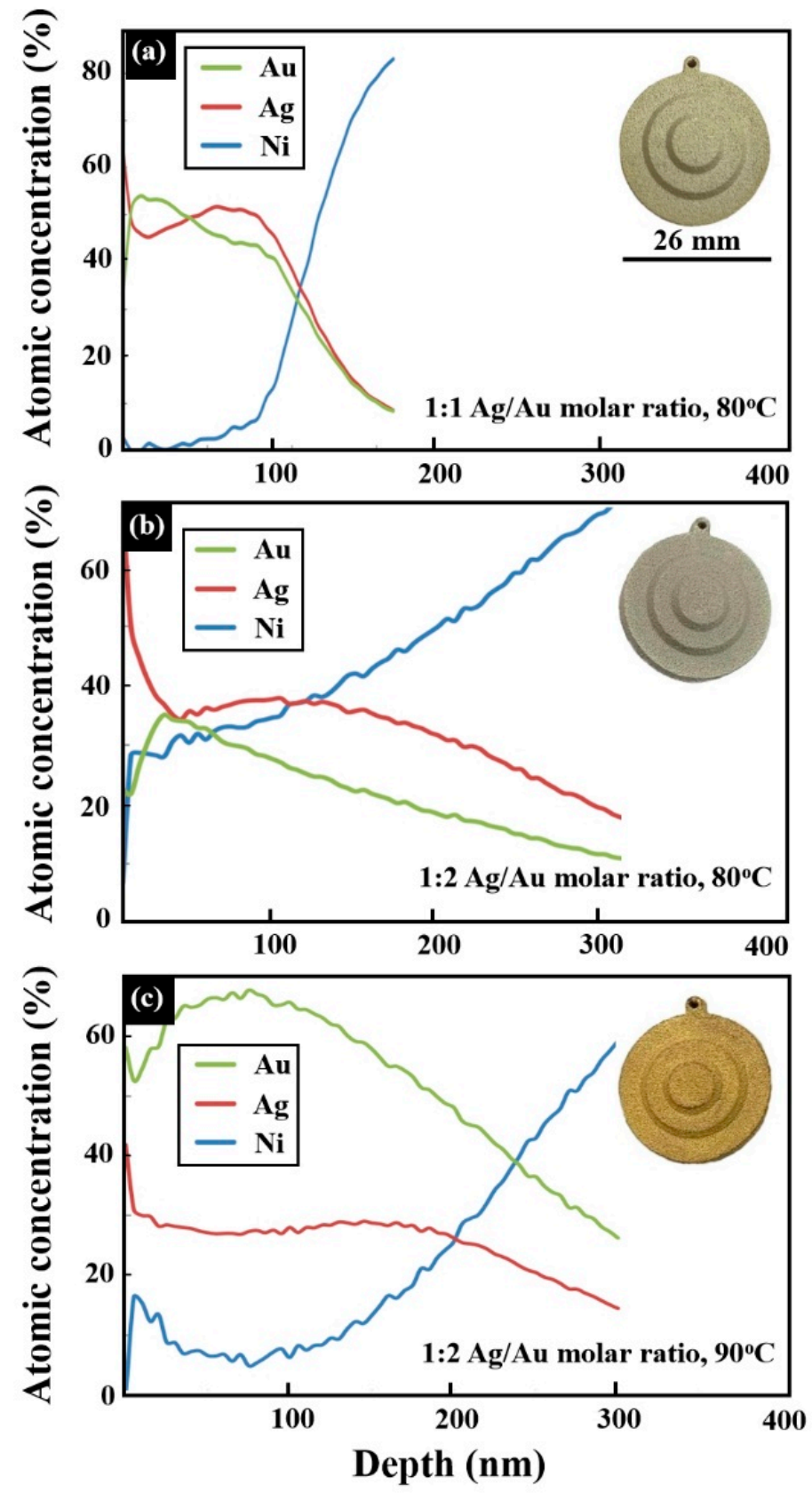

Figure 17. XPS elemental analysis profiles of the $\mathrm{Au}-\mathrm{Ag}$ film coated on the disk-shaped specimen: (a) deposition made with 1:1 Ag/ Au molar ratio in solution at $80^{\circ} \mathrm{C}$; (b) deposition made with 1:2 $\mathrm{Ag} / \mathrm{Au}$ molar ratio in solution at $80^{\circ} \mathrm{C}$; and (c) deposition made with 1:2 Ag/ Au molar ratio in solution at $90^{\circ} \mathrm{C}$.

\section{Discussion}

AM-LPBF technology has great potential for various industrial applications, among them electronics, aerospace, biomedical, heat exchangers, lightweight structures [59], and electric motors [60]. In some AM-LPBF objects, additional post-printing surface modification is needed to improve surface properties.

The current review has been done based on information available in the literature (the last search was done in March 2021) and as a part of an ongoing study performed by the authors $[42,43,48]$. The objective of this study was to review a novel laboratorydeveloped environmental-friendly and low-cost surface finishing process of AM-LPBF AlSi10Mg parts by electroless deposition of gold, silver, and gold-silver alloys, and to propose a methodology suitable for an effective metallization process. For that purpose, 
an introduction is presented, reviewing the manufacturing technology of 3D printing of AlSi10Mg parts by AM-LPBF technology. Next, a literature survey is presented concerning the ELD process of gold, silver, and $\mathrm{Au}-\mathrm{Ag}$ alloys. In the materials and experimental methods part, the fabrication process of AM-LPBF AlSi10Mg specimens is described, including the printing parameters and the chemical composition of the AlSi10Mg powder. Next, the electroless plating processes of $\mathrm{Ag}, \mathrm{Au}$, and $\mathrm{Au}-\mathrm{Ag}$ alloy on top of AM-LPBF AlSi10Mg specimens is described, and the specific bath composition of each coating process is presented. In addition, the characterization methods of Dresler et al. 2019 [42] and Inberg et al. $2020[43,48]$ are presented, while displaying the parameters of each method. In the results part, the final $\mathrm{Ag}$ [42], $\mathrm{Au} \mathrm{[43],} \mathrm{and} \mathrm{Au}-\mathrm{Ag}$ [48] ELD coatings on top of the AM-LPBF AlSi10Mg disk-shaped specimens and their characterization analyses results are presented. This part includes weighed and thickness measurements, qualitative pilling test results, thickness measurements of the $\mathrm{Ag}, \mathrm{Au}, \mathrm{Au}-\mathrm{Ag}$ deposited films, and of the $\mathrm{Ni}-\mathrm{P}$ interlayer, measurements of Ra and RMS roughness values before and after coating, XRD analysis results of the coatings, 3D multi-focal LM, SEM, and FIB-SEM observations of the specimens' surface and their cross-section, and XPS elemental depth profile analysis. Lastly, in the discussion part, the results of the examined Ag, Au, and Au-Ag ELD films are compared and discussed, and a methodology is suggested.

$\mathrm{The} \mathrm{Ag}, \mathrm{Au}$, and $\mathrm{Au}-\mathrm{Ag}$ ELD coatings were chosen based on their esthetic appearance, good corrosion resistance, and their excellent electrical and thermal conductivity. In the case of the electroless silver plating, the thickness of the Ag film grew significantly and linearly during the first $3 \mathrm{~min}$ of the deposition process; then, the thickness growth started to slow down until film thickness saturation was reached (Figure 6a). In the case of the electroless gold plating, at the beginning of the process, the gold deposition rate was lower than the silver deposition rate. Although an acceleration in the Au deposition rate occurred, the coating thickness did not reach saturation (Figure 10a). In the electrum deposition process, the kinetics were similar to the silver deposition process; hence, thickness growth started to slow down with time until saturation of the film thickness was accomplished (Figure 15b).

Only a small reduction of the surface roughness compared to the as-printed AlSi10Mg substrate was observed in all laboratory-developed electroless deposition processes. This may be explained by the thinness of the metal covering of the very rough as-printed LPBF surface. The surface roughness values of the laboratory-developed $\mathrm{Ag}$, $\mathrm{Au}$, and $\mathrm{Au}-\mathrm{Ag}$ coatings were marginally reduced after plating (Figure 6b, Figure 10b, and Figure 16, respectively). Despite the kinetic differences observed in the deposition rate and thickness growth of the $\mathrm{Ag}$, $\mathrm{Au}$, and $\mathrm{Au}-\mathrm{Ag}$ films (Figure 6a, Figure 10a, and Figure 15b, respectively), the decrease in roughness due to the increase in the thickness of the coating is similar for all coated metals (Figures $6 \mathrm{~b}, 10 \mathrm{~b}$ and 16 , respectively); i.e., the roughness decreases as the deposition time increases.

All the laboratory-developed $\mathrm{Ag}, \mathrm{Au}$, and $\mathrm{Au}-\mathrm{Ag}$ films showed a relatively uniform bright surface at the macroscopic level, exhibiting a rather rough topography. At the microscopic level of the laboratory-developed silver and gold deposits, small grains (a range of a few tens to a few hundreds of nanometers) were observed by SEM and multifocal LM (Figures $7 \mathrm{~b}$ and 11b). According to Duhin et al. 2011, the presence of such a tiny grain structure is the result of the usage of nanometric-scale Pd particles, which serve as nucleation sites during the deposition process [61]. Phase identification of the $\mathrm{Au}, \mathrm{Ag}$, and electrum-coated specimens by XRD analysis revealed that the coatings were composed of crystalline phases $[42,43,48]$. The microstructure of the commercial Ag and Au coatings is slightly different, with a smoother macrostructure appearance (Figures $7 \mathrm{~d}$ and 11c). This is due to the use of different manufacturing processes, including bath composition, applied interlayer, and post-deposition heat treatment [42,43]. Elevated temperature heat treatment allows grains to coalescence quickly due to a higher driving force, leading to smoother macrostructures [44,62]. 
FIB-SEM examination of the 3 min silver-coated specimen cross-section (Figure $8 \mathrm{a}, \mathrm{b}$ ) revealed a non-uniform silver film; the thickness varies between 0.5 and $1.0 \mu \mathrm{m}$, following the rough wavy topography of the as-printed AlSi10Mg substrate [42]. Relatively uniform gold and electrum films were attained due to the presence of Ni-P interlayer (Figure 8c,d) [43], with an average thickness of $\approx 0.1 \mu \mathrm{m}$.

Based on the XPS profile analysis of the 1:2 Ag/ Au molar ratio in solution, the thickness of the electrum layer after 3 min of deposition time from a solution with 1:2 Ag/ Au molar ratio was $\approx 0.1 \mu \mathrm{m}$ for $80{ }^{\circ} \mathrm{C}$ and $0.25 \mu \mathrm{m}$ for $90^{\circ} \mathrm{C}$ (Figure $17 \mathrm{~b}, \mathrm{c}$ ). The film thickness determined by XRF and FIB-SEM analyses showed close results. When the electroless deposition (1:2 Ag/ Au molar ratio) was performed at $80^{\circ} \mathrm{C}$, the $\mathrm{Ag}$ was dominant at the beginning of the process. However, when the deposition process (1:2 Ag/ $\mathrm{Au}$ molar ratio) was performed at $90^{\circ} \mathrm{C}$, the Au was first detected on the interface. This can be explained according to the electrochemical properties of the metals and the binding energies needed to form metal-Ni and $\mathrm{Au}-\mathrm{Ag}$ bonding.

The proposed 20-step methodology for effective ELD and characterization of $\mathrm{Au}, \mathrm{Ag}$, and $\mathrm{Au}-\mathrm{Ag}$ films for AM-LPBF AlSi10Mg parts includes three major sections: the AM-LPBF printing process (Figure 18a), the ELD process (Figure 18b), and the full quality characterization of the coating (Figure 18c). The AM-LPBF 3D printing steps are as follows (Figure 18a): (1) materials selection, (2) CAD design, (3) software workflow, (4) object fabrication (printing), (5) post processing, and (6) testing of the printed object. The ELD process steps (Figure 18b) are as follows: (7) functionalization of the surface (-OH/ $-\mathrm{NH}_{2}$ termination), (8) surface sensitization (optional), (9) surface Pd activation, (10) Ni-P electroless deposition (optional), and (11) Au, Ag, or $\mathrm{Au}-\mathrm{Ag}$ electroless deposition. The full characterization of the coating quality includes the use of various measurements and analyses (Figure 18c): (12) dimensions and mass measurements, (13) XRF thickness measurements (14) pilling test, (15) optical profilometry, (16) light microscopy, (17) SEM-EDS analysis, (18) XRD analysis, (19) FIB-SEM, and (20) XPS analysis. It is noteworthy that full-scale characterization is needed only during the development stage of the coating process.

(a) AM-LPBF 3D printing process:

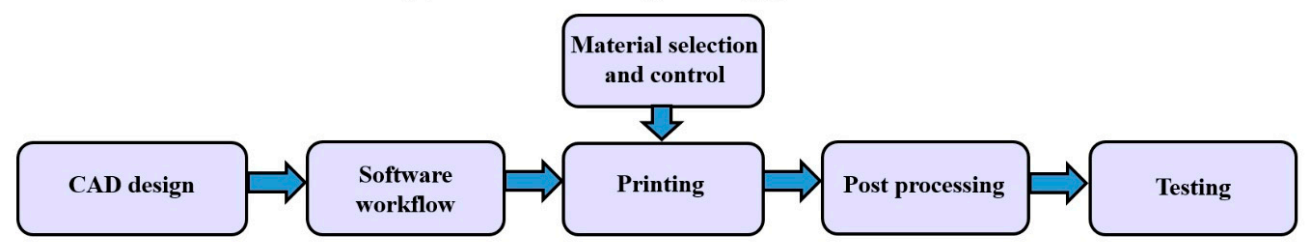

(b) Electroless deposition process:

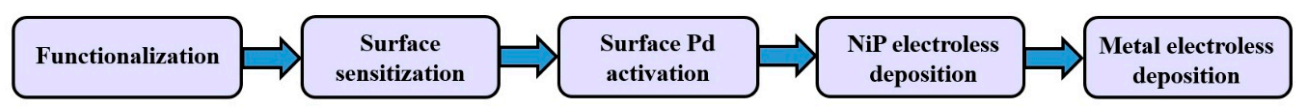

(c) Characterization of the coatings quality:

\begin{tabular}{|c|c|c|c|c|c|c|c|c|}
\hline $\begin{array}{c}\text { Dimensions } \\
\text { and mass } \\
\text { measurements }\end{array}$ & $\begin{array}{c}\text { XRF } \\
\text { thickness } \\
\text { measurements }\end{array}$ & $\begin{array}{c}\text { Pilling } \\
\text { test }\end{array}$ & $\begin{array}{c}\text { Optical } \\
\text { profilometery }\end{array}$ & $\begin{array}{c}\text { Light } \\
\text { microscopy }\end{array}$ & $\begin{array}{c}\text { SEM-EDS } \\
\text { analysis }\end{array}$ & XRD & FIB-SEM & $\begin{array}{c}\text { XPS } \\
\text { analysis }\end{array}$ \\
\hline
\end{tabular}

Figure 18. A schematic illustration of a suggested methodology for effective $\mathrm{Au}, \mathrm{Ag}$, and $\mathrm{Au}-\mathrm{Ag}$ electroless deposition (ELD) coatings of AM-LPBF AlSi10Mg parts: (a) the AM-LPBF process, postprocessing, and quality control; (b) the ELD process steps; and (c) recommended characterization methods for the analysis of the $\mathrm{Au}, \mathrm{Ag}$, and $\mathrm{Au}-\mathrm{Ag}$ ELD films.

\section{Conclusions}

Additive manufactured parts frequently need post-printing surface improvement and modification. The aim of this review was to present a novel laboratory-developed environmental-friendly surface finishing process of AM-LPBF AlSi10Mg parts by elec- 
troless deposition of $\mathrm{Ag}, \mathrm{Au}$, and $\mathrm{Au}-\mathrm{Ag}$ alloys; a relatively simple, low-cost method allowing the coating of conductive and non-conductive materials. The $\mathrm{Ag}, \mathrm{Au}$, and $\mathrm{Au}-\mathrm{Ag}$ were deposited on as-printed disk-shaped specimens using a dedicated surface activation method, and the coating quality was characterized by various methods. The results revealed that the coatings were composed of crystalline phases or mixed quasi-amorphous and nanocrystalline phases. Similar roughness was observed with and without the use of SAM coating, due to the high roughness of the AM-LPBF AlSi10Mg specimens and the submicron thickness of the SAM film. The optional $\approx 1 \mu \mathrm{m}$ Ni-P interlayer improved the adhesion between the substrate and the coated metal, reduced the coated surface roughness, and improved the specimen's overall quality, as shown by the FIB-EDS observations. The roughness of all plated specimens was somewhat reduced as the thickness of the coated layer was increased. In the case of the electrum deposition, at $80^{\circ} \mathrm{C}$, the $\mathrm{Ag}$ was dominant at the beginning of the process, whereas at $90{ }^{\circ} \mathrm{C}$, the $\mathrm{Au}$ was first noticed on the interface. Adequate quality coatings were obtained for all developed electroless deposition processes. A major advantage of the developed $\mathrm{Ag}, \mathrm{Au}, \mathrm{Au}-\mathrm{Ag}$ ELD coatings is the low processing temperature. Another significant benefit of the processes is the avoidance of environmentally hazardous material. The developed finishing processes and the proposed full process methodology are suitable for an effective metallization and can be useful as a post-processing step for many other AM-LPBF printed applications for electrical and thermal conductivity enhancement and to improve the appearance of the part.

Author Contributions: All authors defined the research aims and contributed to the development of the research methodology. A.S. wrote the 'Additive Manufacturing' part of the Introduction, D.A. and A.I. wrote the 'Electroless Plating of Gold, Silver, and Au-Ag Alloys' part of the Introduction. A.S. was in charge of the production of the AM-LPBF AlSi10Mg specimens. A.I. and Y.S.-D. developed the $\mathrm{Au}-\mathrm{Ag}$ coatings, and A.I. prepared the electroless metal coatings. D.A. and A.I. wrote the 'Materials and Experimental Methods'. D.A. and A.I. were in charge of the structure of the publication and D.A. had supervision on the manuscript and was in charge of the figures. All authors discussed the results and contributed to the conclusions. All authors have read and agreed to the published version of the manuscript.

Funding: The author did not receive any specific funding for this work.

Institutional Review Board Statement: Not applicable.

Informed Consent Statement: Not applicable.

Data Availability Statement: Not applicable.

Acknowledgments: The research was supported by the Tel Aviv University and the Afeka Academic College of Engineering to whom the authors are grateful. The authors would like to thank Sharon Tuvia (1982), Ltd. for providing the materials and printing facilities. The authors are thankful to $\mathrm{H}$. Gitler, The Israel Museum Jerusalem, for his advice and encouragement. Thanks are also to N. Dresler, D. Shani, B. Noy, S. Maman, A. Ulanov, and I. Kravchinski, from the Department of Mechanical Engineering, Afeka Academic College of Engineering, for their technical assistance and support. The authors would like to thank G. Kimmel, Department of Materials Engineering, Ben-Gurion University of the Negev, for his assistance with the XRD characterization, and also to I. Rosenthal, Department of Materials Engineering, Ben-Gurion University of the Negev, for his assistance. Thanks are also to M. Tkachev and Y. Fleger from the Institute of Nanotechnology and Advanced Materials, Bar Ilan University, for their assistance with the FIB measurements. The authors would also like to thank E. Leonhardt, HIROX Europe, R. Malmazada and H. Kravits, Microtech LTD (Israel) for their assistance with the HIROX microscope. The authors are thankful to Interplate Ltd., Israel, for the commercial silver and gold coatings and to Barbara Doron for the English editing.

Conflicts of Interest: The authors declare no conflict of interest.

\section{References}

1. Li, W.; Li, S.; Liu, J.; Zhang, A.; Zhou, Y.; Wei, Q.; Yan, C.; Shi, Y. Effect of heat treatment on AlSi10Mg alloy fabricated by selective laser melting: Microstructure evolution, mechanical properties and fracture mechanism. Mater. Sci. Eng. A 2016, 663, 116-125. [CrossRef] 
2. Aboulkhair, N.T.; Tuck, C.; Ashcroft, I.; Maskery, I.; Everitt, N.M. On the precipitation hardening of selective laser melted AlSi10Mg. Met. Mater. Trans. A 2015, 46, 3337-3341. [CrossRef]

3. Zhou, L.; Mehta, A.; Schulz, E.; McWilliams, B.; Cho, K.; Sohn, Y. Microstructure, precipitates and hardness of selectively laser melted AlSi10Mg alloy before and after heat treatment. Mater. Charact. 2018, 143, 5-17. [CrossRef]

4. Van Cauwenbergh, P.; Samaee, V.; Thijs, L.; Nejezchlebová, J.; Sedlák, P.; Iveković, A.; Schryvers, D.; Van Hooreweder, B.; Vanmeensel, K. Unravelling the multi-scale structure-property relationship of laser powder bed fusion processed and heattreated AlSi10Mg. Sci. Rep. 2021, 11, 1-15. [CrossRef] [PubMed]

5. Macías, J.G.S.; Douillard, T.; Zhao, L.; Maire, E.; Pyka, G.; Simar, A. Influence on microstructure, strength and ductility of build platform temperature during laser powder bed fusion of AlSi10Mg. Acta Mater. 2020, 201, 231-243. [CrossRef]

6. Kusoglu, I.M.; Gökce, B.; Barcikowski, S. Research trends in laser powder bed fusion of Al alloys within the last decade. Addit. Manuf. 2020, 36, 101489. [CrossRef]

7. Rosenthal, I.; Stern, A.; Frage, N. Strain rate sensitivity and fracture mechanism of AlSi10Mg parts produced by selective laser melting. Mater. Sci. Eng. A 2017, 682, 509-517. [CrossRef]

8. Zaretsky, E.; Stern, A.; Frage, N. Dynamic response of AlSi10Mg alloy fabricated by selective laser melting. Mater. Sci. Eng. A 2017, 688, 364-370. [CrossRef]

9. Yang, T.; Liu, T.; Liao, W.; MacDonald, E.; Wei, H.; Chen, X.; Jiang, L. The influence of process parameters on vertical surface roughness of the AlSi10Mg parts fabricated by selective laser melting. J. Mater. Process. Technol. 2019, 266, 26-36. [CrossRef]

10. Steuben, J.C.; Birnbaum, A.J.; Michopoulos, J.G.; Iliopoulos, A.P. Enriched analytical solutions for additive manufacturing modeling and simulation. Addit. Manuf. 2019, 25, 437-447. [CrossRef]

11. Whip, B.; Sheridan, L.; Gockel, J. The effect of primary processing parameters on surface roughness in laser powder bed additive manufacturing. Int. J. Adv. Manuf. Technol. 2019, 103, 4411-4422. [CrossRef]

12. Boschetto, A.; Bottini, L.; Veniali, F. Roughness modeling of AlSi10Mg parts fabricated by selective laser melting. J. Mater. Process. Technol. 2017, 241, 154-163. [CrossRef]

13. Nahmany, M.; Hadad, Y.; Aghion, E.; Stern, A.; Frage, N. Microstructural assessment and mechanical properties of electron beam welding of AlSi10Mg specimens fabricated by selective laser melting. J. Mater. Process. Technol. 2019, 270, 228-240. [CrossRef]

14. Park, T.H.; Baek, M.S.; Sohn, Y.; Lee, K.A. Effect of post-heat treatment on the wear properties of AlSi10Mg alloy manufactured by selective laser melting. Arch. Metall. Mater. 2020, 65, 1073-1080. [CrossRef]

15. Han, Q.; Jiao, Y. Effect of heat treatment and laser surface remelting on AlSi10Mg alloy fabricated by selective laser melting. Int. J. Adv. Manuf. Technol. 2019, 102, 3315-3324. [CrossRef]

16. Lee, S.; Wajahat, M.; Kim, J.H.; Pyo, J.; Chang, W.S.; Cho, S.H.; Kim, J.T.; Seol, S.K. Electroless Deposition-assisted 3D printing of micro circuitries for structural electronics. ACS Appl. Mater. Interfaces 2019, 11, 7123-7130. [CrossRef]

17. Kuo, C.-C.; Wang, C.-W.; Lee, Y.-F.; Liu, Y.-L.; Qiu, Q.-Y. A surface quality improvement apparatus for ABS parts fabricated by additive manufacturing. Int. J. Adv. Manuf. Technol. 2016, 89, 635-642. [CrossRef]

18. Han, Q.; Gu, H.; Soe, S.; Setchi, R.; Lacan, F.; Hill, J. Manufacturability of AlSi10Mg overhang structures fabricated by laser powder bed fusion. Mater. Des. 2018, 160, 1080-1095. [CrossRef]

19. Inberg, A.; Shacham-Diamand, Y.; Rabinovich, E.; Golan, G.; Croitoru, N. Electroless-deposited Ag-W films for microelectronics applications. Thin Solid Films 2001, 389, 213-218. [CrossRef]

20. Estrada-Raygoza, I.; Sotelo-Lerma, M.; Ramírez-Bon, R. Structural and morphological characterization of chemically deposited silver films. J. Phys. Chem. Solids 2006, 67, 782-788. [CrossRef]

21. Asher, T.; Inberg, A.; Glickman, E.; Fishelson, N.; Shacham-Diamand, Y. Formation and characterization of low resistivity sub-100nm copper films deposited by electroless on SAM. Electrochim. Acta 2009, 54, 6053-6057. [CrossRef]

22. Inberg, A.; Livshits, P.; Zalevsky, Z.; Shacham-Diamand, Y. Electroless deposition of silver thin films on gold nanoparticles catalyst for micro and nanoelectronics applications. Microelectron. Eng. 2012, 98, 570-573. [CrossRef]

23. Duhin, A.; Inberg, A.; Eliaz, N.; Gileadi, E. Electroless plating of rhenium-based alloys with nickel, cobalt and iron. Electrochim. Acta 2015, 174, 660-666. [CrossRef]

24. Lelevic, A.; Walsh, F.C. Electrodeposition of NiP composite coatings: A review. Surf. Coat. Tech. 2019, 378, 124803. [CrossRef]

25. Paunovic, M. Electrochemical aspects of electroless deposition of metals. Plating 1968, 55, 1161-1167.

26. Shacham-Diamand, Y.; Inberg, A.; Sverdlov, Y.; Croitoru, N. Electroless silver and silver with tungsten thin films for microelectronics and microelectromechanical system applications. J. Electrochem. Soc. 2000, 147, 3345-3349. [CrossRef]

27. Shukla, S.; Gomathi, N.; George, R. Autocatalytic silver-plating of aluminum radio frequency waveguides with autocatalytic nickel as the undercoat for space applications. Surf. Topogr. Metrol. Prop. 2014, 2, 045004. [CrossRef]

28. Shacham-Diamand, Y.; Osaka, T.; Okinaka, Y.; Sugiyama, A.; Dubin, V. 30 years of electroless plating for semiconductor and polymer micro-systems. Microelectron. Eng. 2015, 132, 35-45. [CrossRef]

29. Brenner, A.; Riddell, G. Nickel plating on steel by chemical reduction. J. Res. Natl. Inst. Stand. Technol. 1946, 37, 31. [CrossRef]

30. Wang, C.; Farhat, Z.; Jarjoura, G.; Hassan, M.K.; Abdullah, A.M. Indentation and erosion behavior of electroless Ni-P coating on pipeline steel. Wear 2017, 376-377, 1630-1639. [CrossRef]

31. Cui, C.; Du, H.; Liu, H.; Xiong, T. Corrosion behavior of the electroless Ni-P coating on the pore walls of the lotus-type porous copper. Corros. Sci. 2020, 162, 108202. [CrossRef] 
32. Guo, Z.; Keong, K.; Sha, W. Crystallisation and phase transformation behaviour of electroless nickel phosphorus platings during continuous heating. J. Alloys Compd. 2003, 358, 112-119. [CrossRef]

33. Wang, J.; Wu, Q. The effects of anodic interlayer on the morphology and mechanical performances of electroless Ni-P coating on Al alloy. Appl. Phys. A 2017, 123, 435. [CrossRef]

34. Tsaia, T.K.; Chao, C.G. The growth morphology and crystallinity of electroless NiP deposition on silicon. Appl. Surf. Sci. 2004, 233, 180-190. [CrossRef]

35. Ashkenazi, D.; Gitler, H.; Stern, A.; Tal, O. Metallurgical investigation on fourth century BCE silver jewellery of two hoards from Samaria. Sci. Rep. 2017, 7, 40659. [CrossRef] [PubMed]

36. Fishelson, N.; Inberg, A.; Croitoru, N.; Shacham-Diamand, Y. Highly corrosion resistant bright silver metallization deposited from a neutral cyanide-free solution. Microelectron. Eng. 2012, 92, 126-129. [CrossRef]

37. Zhang, H.; Shen, L.; Chang, J. Comparative study of electroless Ni-P, Cu, Ag, and Cu-Ag plating on polyamide fabrics. J. Ind. Text. 2010, 41, 25-40. [CrossRef]

38. Liu, S.; Chen, G.; Prasad, P.N.; Swihart, M.T. Synthesis of monodisperse Au, Ag, and Au-Ag alloy nanoparticles with tunable size and surface plasmon resonance frequency. Chem. Mater. 2011, 23, 4098-4101. [CrossRef]

39. Hough, R.M.; Butt, C.R.M.; Fischer-Bühner, J. The crystallography, metallography and composition of gold. Elements 2009, 5, 297-302. [CrossRef]

40. Troalen, L.G.; Tate, J.; Guerra, M.F. Goldwork in ancient Egypt: Workshop practices at Qurneh in the 2nd Intermediate Period. J. Archaeol. Sci. 2014, 50, 219-226. [CrossRef]

41. Suematsu, Y.; Saito, K.; Koyama, M.; Enokida, Y.; Okura, Y.; Nakayasu, T.; Sukegawa, T. Development of micro-mirror slicer integral field unit for space-borne solar spectrographs. CEAS Space J. 2017, 9, 421-431. [CrossRef]

42. Dresler, N.; Inberg, A.; Ashkenazi, D.; Shacham-Diamand, Y.; Stern, A. Silver electroless finishing of selective laser melting 3D-printed AlSi10Mg artifacts. Met. Microstruct. Anal. 2019, 8, 678-692. [CrossRef]

43. Inberg, A.; Ashkenazi, D.; Kimmel, G.; Shacham-Diamand, Y.; Stern, A. Gold plating of AlSi10Mg parts produced by a laser powder-bed fusion additive manufacturing technique. Prog. Addit. Manuf. 2020, 5, 395-404. [CrossRef]

44. Akben, K.; Timur, S. A study of gold-silver alloy electrodeposited from pyrophosphate-cyanide electrolyte using polyethylenimine-KSeCN additives. Int. J. Electrochem. Sci. 2018, 13, 3855-3873. [CrossRef]

45. Huang, T. Electrodeposited silver-gold alloy as a sensor for paracetamol determination. Int. J. Electrochem. Sci. 2017, 12, 11419-11427. [CrossRef]

46. Márquez, K.; Staikov, G.; Schultze, J.W. Electrochemical deposition of Ag, Au and Ag-Au alloys on n-Si(111). Trans. IMF 2002, 80, 73-78. [CrossRef]

47. Stansfield, G.L.; Johnston, H.M.; Baxter, S.N.; Thomas, P.J. Deposition of Ag and Ag-Au nanocrystalline films with tunable conductivity at the water-toluene interface. RSC Adv. 2018, 8, 6225-6230. [CrossRef]

48. Inberg, A.; Ashkenazi, D.; Kimmel, G.; Shacham-Diamand, Y.; Stern, A. Gold-silver electroless plating on laser powder-bed fusion additively printed AlSi10Mg parts. Metals 2020, 10, 557. [CrossRef]

49. Shani, D.; Inberg, A.; Ashkenazi, D.; Shacham-Diamand, Y.; Stern, A. Gold plating on AM-FDM ABS components. Ann. Dunarea Jos Univ. Galati. Fascicle XII Weld. Equip. Technol. 2019, 30, 43-50. [CrossRef]

50. Olivera, S.; Muralidhara, H.B.; Venkatesh, K.; Gopalakrishna, K.; Vivek, C.S. Plating on acrylonitrile-butadiene-styrene (ABS) plastic: A review. J. Mater. Sci. 2016, 51,3657-3674. [CrossRef]

51. Yoshino, M.; Masuda, T.; Yokoshima, T.; Sasano, J.; Shacham-Diamand, Y.; Matsuda, I.; Osaka, T.; Hagiwara, Y.; Sato, I. Electroless diffusion barrier process using SAM on Low-k dielectrics. J. Electrochem. Soc. 2007, 154, D122-D125. [CrossRef]

52. Ulman, A. Formation and structure of self-assembled monolayers. Chem. Rev. 1996, 96, 1533-1554. [CrossRef] [PubMed]

53. Schreiber, F. Structure and growth of self-assembling monolayers. Prog. Surf. Sci. 2000, 65, 151-257. [CrossRef]

54. Ashkenazi, D.; Nusbaum, I.; Shacham-Diamand, Y.; Cvikel, D.; Kahanov, Y.; Inberg, A. A method of conserving ancient iron artefacts retrieved from shipwrecks using a combination of silane self-assembled monolayers and wax coating. Corros. Sci. 2017, 123, 88-102. [CrossRef]

55. Krusenstern, A. Galvanotechnik of Noble Metals; Metallurgy: Moscow, Russia, 1974; p. 91. (In Russian)

56. Werner, K.; Nolze, G. Powder cell-A program for the representation and manipulation of crystal structures and calculation of the resulting X-ray powder patterns. J. Appl. Cryst. 1996, 29, 301-303.

57. Ashkenazi, D.; Cvikel, D. A journey into the microstructure: Using a multifocal 3D digital light microscope to study archaeological artefacts retrieved from shipwrecks. Digit. Appl. Archaeol. Cult. Heritage 2020, 16, e00129. [CrossRef]

58. Reiher, T.; Lindemann, C.; Jahnke, U.; Deppe, G.; Koch, R. Holistic approach for industrializing AM technology: From part selection to test and verification. Prog. Addit. Manuf. 2017, 2, 43-55. [CrossRef]

59. Ngo, T.D.; Kashani, A.; Imbalzano, G.; Nguyen, K.T.; Hui, D. Additive manufacturing (3D printing): A review of materials, methods, applications and challenges. Compos. Part. B Eng. 2018, 143, 172-196. [CrossRef]

60. Silbernagel, C.; Ashcroft, I.; Dickens, P.; Galea, M. Electrical resistivity of additively manufactured AlSi10Mg for use in electric motors. Addit. Manuf. 2018, 21, 395-403. [CrossRef]

61. Duhin, A.; Inberg, A.; Eliaz, N.; Gileadi, E. Electroless plating of rhenium-nickel alloys. Electrochim. Acta 2011, 56, 9637-9643. [CrossRef] 
62. Guisbiers, G.; Mendoza-Cruz, R.; Bazán-Díaz, L.; Velázquez-Salazar, J.J.; Mendoza-Perez, R.; Robledo-Torres, J.A.; RodriguezLopez, J.-L.; Montejano-Carrizales, J.M.; Whetten, R.L.; José-Yacamán, M. Electrum, the Gold-Silver Alloy, from the Bulk Scale to the Nanoscale: Synthesis, Properties, and Segregation Rules. ACS Nano 2016, 10, 188-198. [CrossRef] [PubMed] 